NATIONAL LABORATORY

\title{
Laboratory Studies of the Effects of Static and Variable Magnetic Fields on Freshwater Fish
}

\section{April 2012}

\section{Prepared by}

Glenn F. Cada, Mark S. Bevelhimer, Allison M. Fortner, Kristina P. Riemer, and Peter E. Schweizer

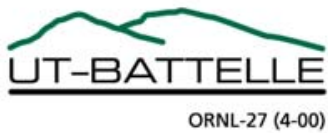




\section{DOCUMENT AVAILABILITY}

Reports produced after January 1, 1996, are generally available free via the U.S. Department of Energy (DOE) Information Bridge.

Web site http://www.osti.gov/bridge

Reports produced before January 1, 1996, may be purchased by members of the public from the following source.

National Technical Information Service

5285 Port Royal Road

Springfield, VA 22161

Telephone 703-605-6000 (1-800-553-6847)

TDD 703-487-4639

Fax 703-605-6900

E-mail info@ntis.gov

Web site http://www.ntis.gov/support/ordernowabout.htm

Reports are available to DOE employees, DOE contractors, Energy Technology Data Exchange (ETDE) representatives, and International Nuclear Information System (INIS) representatives from the following source.

Office of Scientific and Technical Information

P.O. Box 62

Oak Ridge, TN 37831

Telephone 865-576-8401

Fax 865-576-5728

E-mail reports@osti.gov

Web site http://www.osti.gov/contact.html

This report was prepared as an account of work sponsored by an agency of the United States Government. Neither the United States Government nor any agency thereof, nor any of their employees, makes any warranty, express or implied, or assumes any legal liability or responsibility for the accuracy, completeness, or usefulness of any information, apparatus, product, or process disclosed, or represents that its use would not infringe privately owned rights. Reference herein to any specific commercial product, process, or service by trade name, trademark, manufacturer, or otherwise, does not necessarily constitute or imply its endorsement, recommendation, or favoring by the United States Government or any agency thereof. The views and opinions of authors expressed herein do not necessarily state or reflect those of the United States Government or any agency thereof. 


\title{
LABORATORY STUDIES OF THE EFFECTS
} OF STATIC AND VARIABLE MAGNETIC FIELDS ON FRESHWATER FISH

\author{
G. F. Cada \\ M. S. Bevelhimer \\ A. M. Fortner \\ K. P. Riemer \\ P. E. Schweizer
}

Date Published: April 2012

\author{
Prepared for the \\ Water Power Program \\ Office of Energy Efficiency and Renewable Energy \\ U.S. Department of Energy \\ Washington, DC \\ Prepared by \\ OAK RIDGE NATIONAL LABORATORY \\ Oak Ridge, Tennessee 37831-6283 \\ managed by \\ UT-BATTELLE, LLC \\ for the \\ U.S. DEPARTMENT OF ENERGY \\ under contract DE-AC05-00OR22725
}





\section{CONTENTS}

\section{Page}

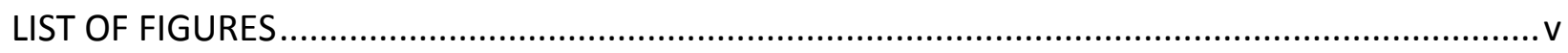

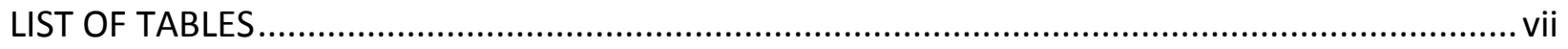

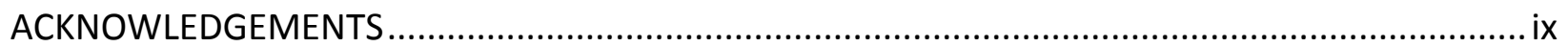

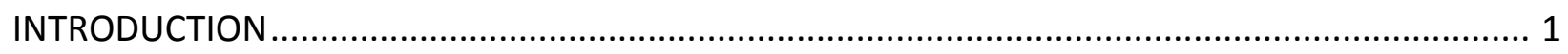

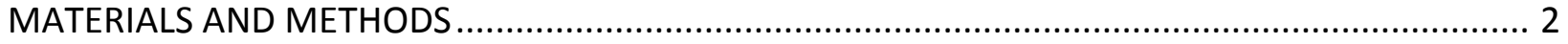

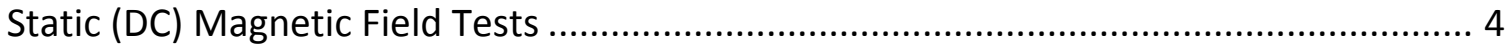

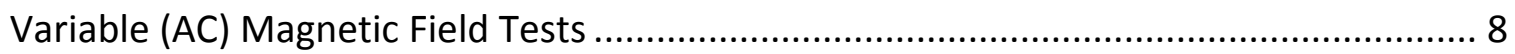

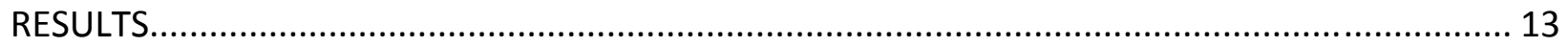

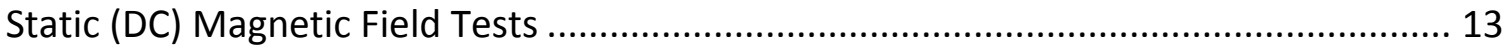

Variable (AC) Magnetic Field Tests ....................................................................... 20

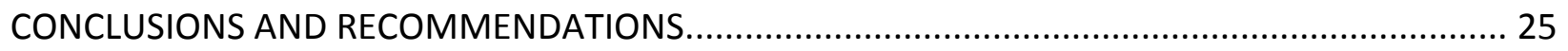

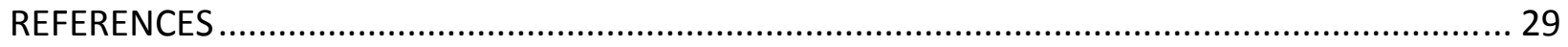





\section{LIST OF FIGURES}

Figure

Page

1 AC magnetic field profiles across the surface of the seabed for 10 submarine cable

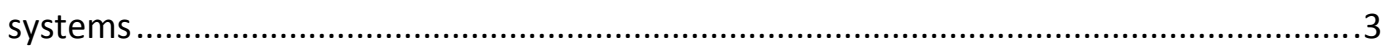

2 DC magnetic field calculated at seabed surface for 9 submarine projects using buried bipolar and monopolar (with cable return) HVDC undersea cables ...................................

3 Calculated magnetic field near an unshielded DC electrical transmission line..................4

$4 \quad$ Strength $(\mu \mathrm{T})$ of the static magnetic field created within each aquarium placed over a

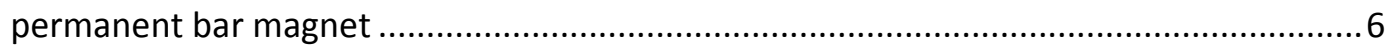

$5 \quad$ Experimental setup for the static magnetic field (DC) experiments .................................

6 Experimental tank used to test the response of fish to variable magnetic fields created

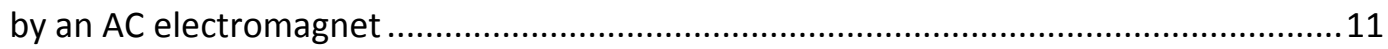

$7 \quad$ Magnetic field produced at the inside wall of an experimental tank by an AC electromagnet set at four strengths: (a) $100 \%$, (b) $50 \%$, (c) $5 \%$, and (d) $1 \%$

8 (A) Occurrences (total number of observations) of individual fathead minnows (red lines) on the north and south sides (control treatments) and on the magnetized and non-magnetized sides (experimental treatments).....

9 (A) Occurrences (total number of observations) of individual sunfish (red lines) on the north and south sides (control treatments) and on the magnetized and nonmagnetized sides (experimental treatments)

(A) Occurrences (total number of observations) of individual striped bass (red lines) on the north and south sides (control treatments) and on the magnetized and nonmagnetized sides (experimental treatments)

11 (A) Occurrences (total number of observations) of individual catfish (red lines) on the north and south sides (control treatments) and on the magnetized and nonmagnetized sides (experimental treatments)

Occurrences (total number of observations) of individual channel catfish ( $n=12)$ inside and outside of huts from treatment tanks for sides with a magnet and sides without a magnet Proportion of trials in which juvenile lake sturgeon responded to sudden exposure to variable EMF, and mean number of responses by fish and trial.

14 Juvenile sturgeon behavior responses observed most frequently in response to the variable magnetic field 



\section{LIST OF TABLES}

Table

Page

$1 \quad$ Locations of individual fathead minnows during static magnetic field exposure experiments...... .15

2 Behavioral responses of juvenile sunfish (Lepomis spp.) to a strong variable (ACgenerated) electromagnetic pulse ..........................................................................21

3 Summary of paddlefish and lake sturgeon behaviors observed following exposure to variable $(\mathrm{AC})$ magnetic fields

4 Summary of experiments and reactions of fish following exposure to a variable (AC-

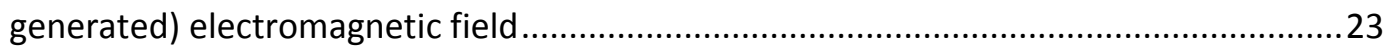

5 Summary of responses to static magnetic field exposure in examined fish species ........26 



\section{ACKNOWLEDGEMENTS}

The juvenile catfish and striped bass were obtained from the Tennessee Wildlife Resource Agency's Eagle Bend Fish Hatchery in Clinton, Tennessee. We thank Mike Smith and his staff for their generous assistance. We thank Lee Friedlander of the Tennessee Aquarium Conservation Institute in Chattanooga, Tennessee for supplying the juvenile lake sturgeon. The paddlefish were obtained from Tim Parrott of Aquila International, Inc. in Versailles, Kentucky.

We thank John Wilgen for his advice and calculations of magnetic field strength and John Smith for statistical advice. Jocelyn Brown-Saracino, Hoyt Battey, and Anna Coffey provided valuable suggestions on an earlier draft of this report.

This research was supported by the U.S. Department of Energy's (DOE) Office of Energy Efficiency and Renewable Energy, Water Power Program. Oak Ridge National Laboratory is managed by UT-Battelle, LLC, for the DOE under contract DE-AC05-00OR22725. 



\section{INTRODUCTION}

There is considerable interest in the development of marine and hydrokinetic energy projects in rivers, estuaries, and coastal ocean waters of the United States. Hydrokinetic (HK) technologies convert the energy of moving water in river or tidal currents into electricity, without the impacts of dams and impoundments associated with conventional hydropower or the extraction and combustion of fossil fuels. The Federal Energy Regulatory Commission (FERC) maintains a database that displays the geographical distribution of proposed HK projects in inland and tidal waters (FERC 2012). As of March 2012, 77 preliminary permits had been issued to private developers to study HK projects in inland waters, the development of which would total over 8,000 MW. Most of these projects are proposed for the lower Mississippi River. In addition, the issuance of another 27 preliminary permits for HK projects in inland waters, and 3 preliminary permits for HK tidal projects (totaling over 3,100 MW) were under consideration by FERC. Although numerous HK designs are under development (see DOE 2009 for a description of the technologies and their potential environmental effects), the most commonly proposed projects entail arrays of rotating devices, much like submerged wind turbines, that are positioned in the high-velocity (high energy) river channels.

The many diverse HK designs imply a diversity of environmental impacts, but a potential impact common to most is the effect on aquatic organisms of electromagnetic fields (EMF) created by the projects. The submerged electrical generator will emit an EMF into the surrounding water, as will underwater cables used to transmit electricity from the generator to the shore, between individual units in an array (inter-turbine cables), and between the array and a submerged step-up transformer. The electric current moving through these cables will induce magnetic fields in the immediate vicinity, which may affect the behavior or viability of fish and benthic invertebrates (Gill et al. 2005, 2009). It is known that numerous marine and freshwater organisms are sensitive to electrical and magnetic fields, often depending on them for such diverse activities as prey location and navigation (DOE 2009; Normandeau et al. 2011). Despite the wide range of aquatic organisms that are sensitive to EMF and the increasing numbers of underwater electrical transmitting cables being installed in rivers and coastal waters, little information is available to assess whether animals will be attracted, repelled, or unaffected by these new sources of EMF. This knowledge gap is especially significant for freshwater systems, where electrosensitive organisms such as paddlefish and sturgeon may interact with electrical transmission cables.

We carried out a series of laboratory experiments to test the sensitivity of freshwater fish and invertebrates to the levels of EMF that are expected to be produced by HK projects in rivers. In this context, EM fields are likely to be emitted primarily by generators in the water column and by transmission cables on or buried in the substrate. The HK units will be located in areas of high-velocity waters that are used as only temporary habitats for most riverine species, so long-term exposure of fish and benthic invertebrates to EMF is unlikely. Rather, most aquatic organisms will be briefly exposed to the fields as they drift downstream or migrate upstream. Because the exposure of most aquatic organisms to EMF in a river would be relatively brief and non-lethal, we focused our investigations on detecting behavioral effects. For example, attraction to the EM fields could result in prolonged exposures to the fields or the HK rotor. On the other hand, avoidance reactions might hinder upstream 
migrations of fish. The experiments reported here are a continuation of studies begun in FY 2010, which focused on the potential effects of static magnetic fields on snails, clams, and fathead minnows (Cada et al. 2011). Those experiments found little indication that the behaviors of these freshwater species were altered by the static magnetic fields that would be created by submerged, direct current (DC)transmitting electrical cables expected to be used by the HK developers. Laboratory experiments in FY 2011 examined the responses of additional fish species (sunfish, striped bass, and channel catfish) to the static magnetic fields. In addition, the effects of variable magnetic fields (that would be created by the HK generators and AC-transmitting cables) on swimming behavior of two electrosensitive fish species (paddlefish and lake sturgeon) were studied.

\section{MATERIALS AND METHODS}

EMF will be emitted by the HK generator, transformers, rectifiers, and the electrical cables used to transmit the power to shore. A variable magnetic field will be created by alternating current (AC) generating and transmitting components of an HK project. These components will include the submerged generator and possibly short transmission cables running from the generator to a rectifier that converts AC to DC. Commonly, the longer electrical cables leading to the shoreline will be designed to conduct high voltage direct current (HVDC), which will produce a static magnetic field.

Proper shielding and insulation of the components will prevent leakage of electricity (direct electric field emissions), but they cannot completely shield the magnetic (B) field or the consequent induced electrical field (iE) (Gill et al. 2005). Similarly, burying the cable will not dampen the magnetic field. However, because the B field is strongest at the surface of the cable and declines rapidly with distance, burying the cable in sediment may reduce effects on sensitive fish simply by increasing the separation distance (CMACS 2003).

Design characteristics of 24 undersea cables were used to model the expected magnetic fields to which marine organisms may be exposed (Normandeau et al. 2011). For both AC and DC cables, the predicted strength of the magnetic fields was greatest at the surface of the cable and declined rapidly with vertical and horizontal distance. Maximum levels for the 10 modeled AC submarine cables were about $18 \mu T$ (Figure 1). Magnetic fields for DC cables peaked at about $275 \mu \mathrm{T}$, although most cables were predicted to create a maximum field strength less than $150 \mu \mathrm{T}$ (Figure 2).

Estimates of the magnetic field at various distances from a hypothetical unshielded DC transmission cable are shown in Figure 3. For the case shown, it is assumed that the current is 1,000 amps, that the two conductors are spaced $0.1 \mathrm{~m}$ apart (located at $\pm 0.05 \mathrm{~m}$ ) inside of a cable assembly that is $0.2 \mathrm{~m}$ in diameter (extending from -0.1 to $+0.1 \mathrm{~m}$ ). The magnetic B-field was calculated in the plane perpendicular to the plane of a pair of current-carrying conductors with equal and oppositely directed current; consequently, this estimate applies both to a DC transmission line and also to a 3-phase power line at the instant in time when the current in one of the conductors passes through 0 value for the current, at which point in time the currents on the other two conductors are equal and opposite direction. In this example, the maximum calculated magnetic field at the surface of the power cable 


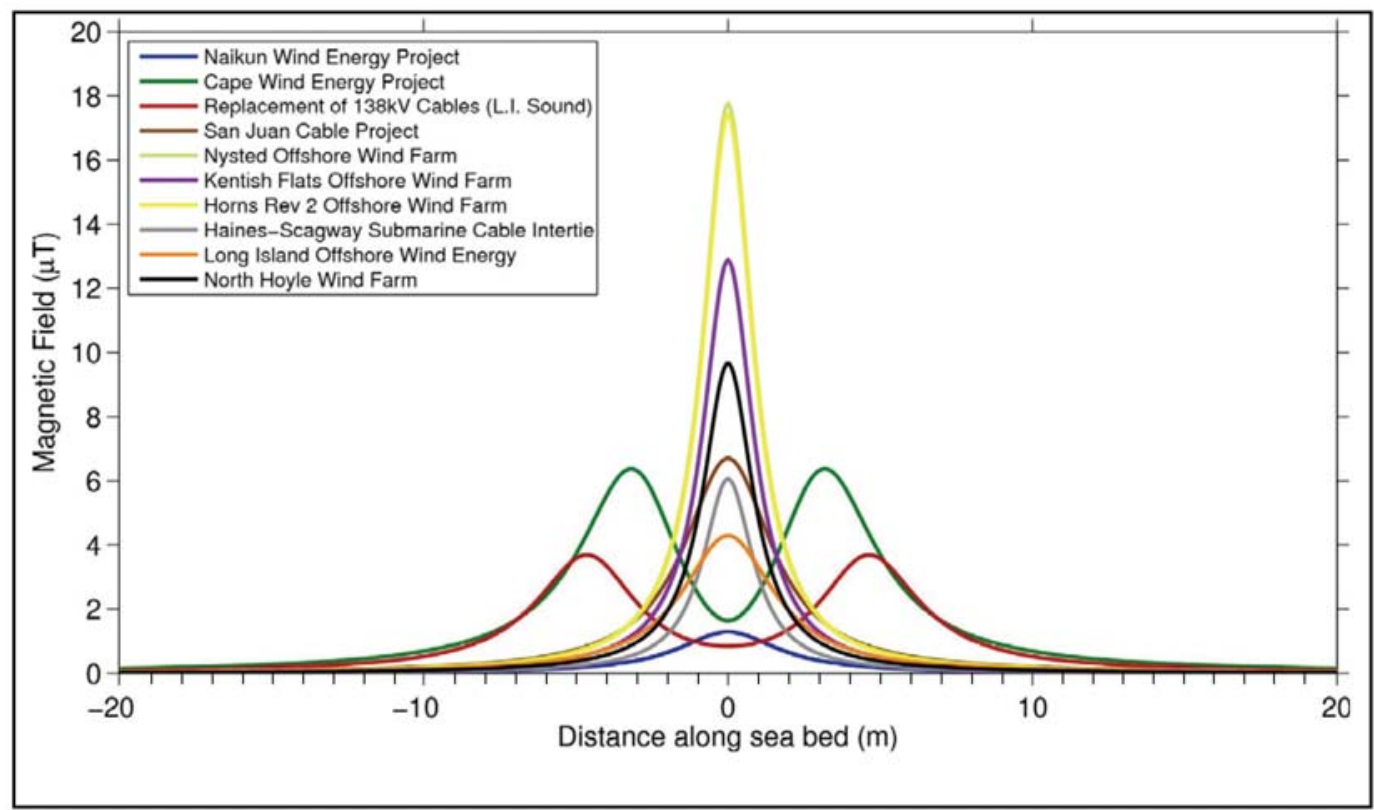

Figure 1. A magnetic field profiles across the surface of the seabed for 10 submarine cable systems.

Source: Normandeau et al. 2011.

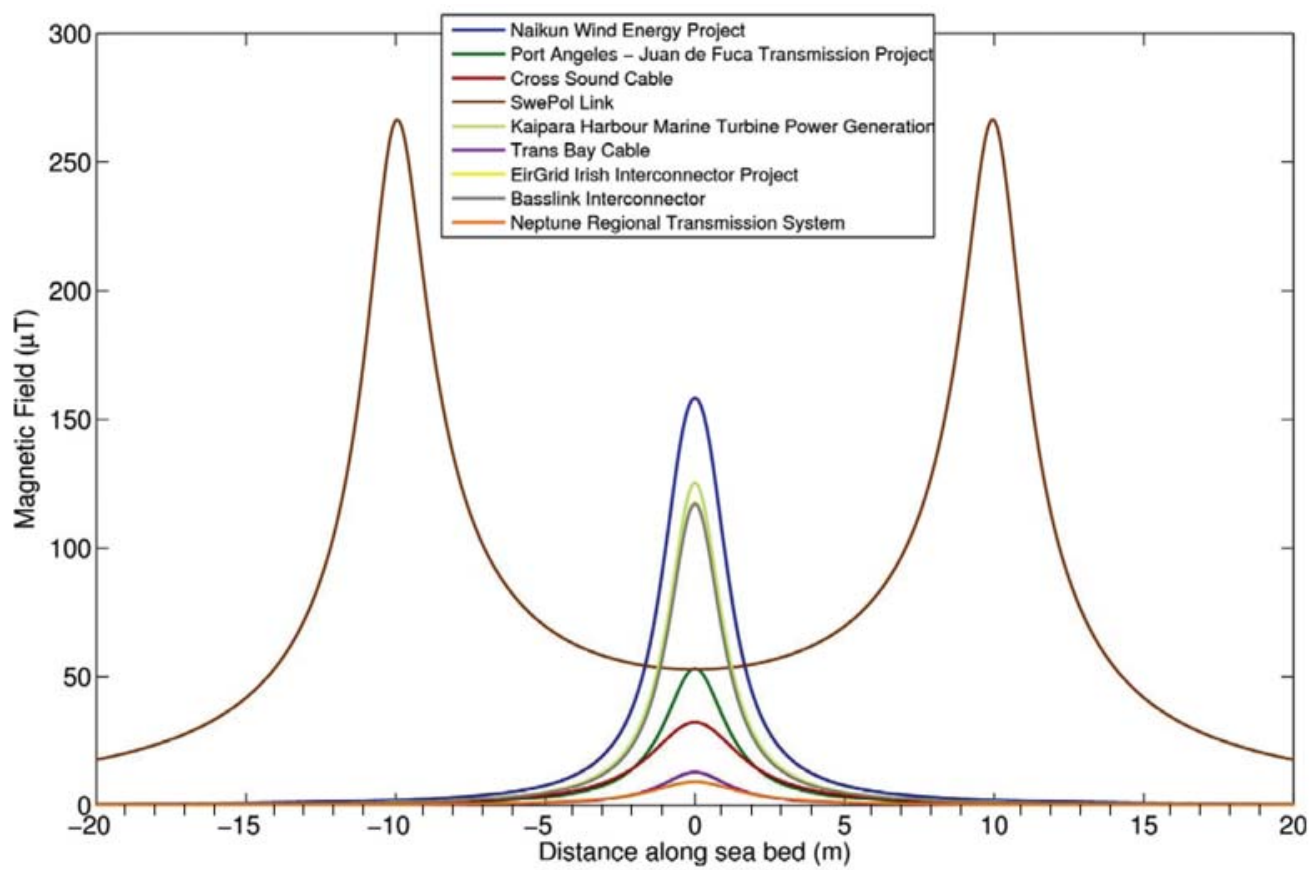

Figure 2. DC magnetic field calculated at seabed surface for 9 submarine projects using buried bipolar and monopolar (with cable return) HVDC undersea cables.

Source: Normandeau et al. 2011. 


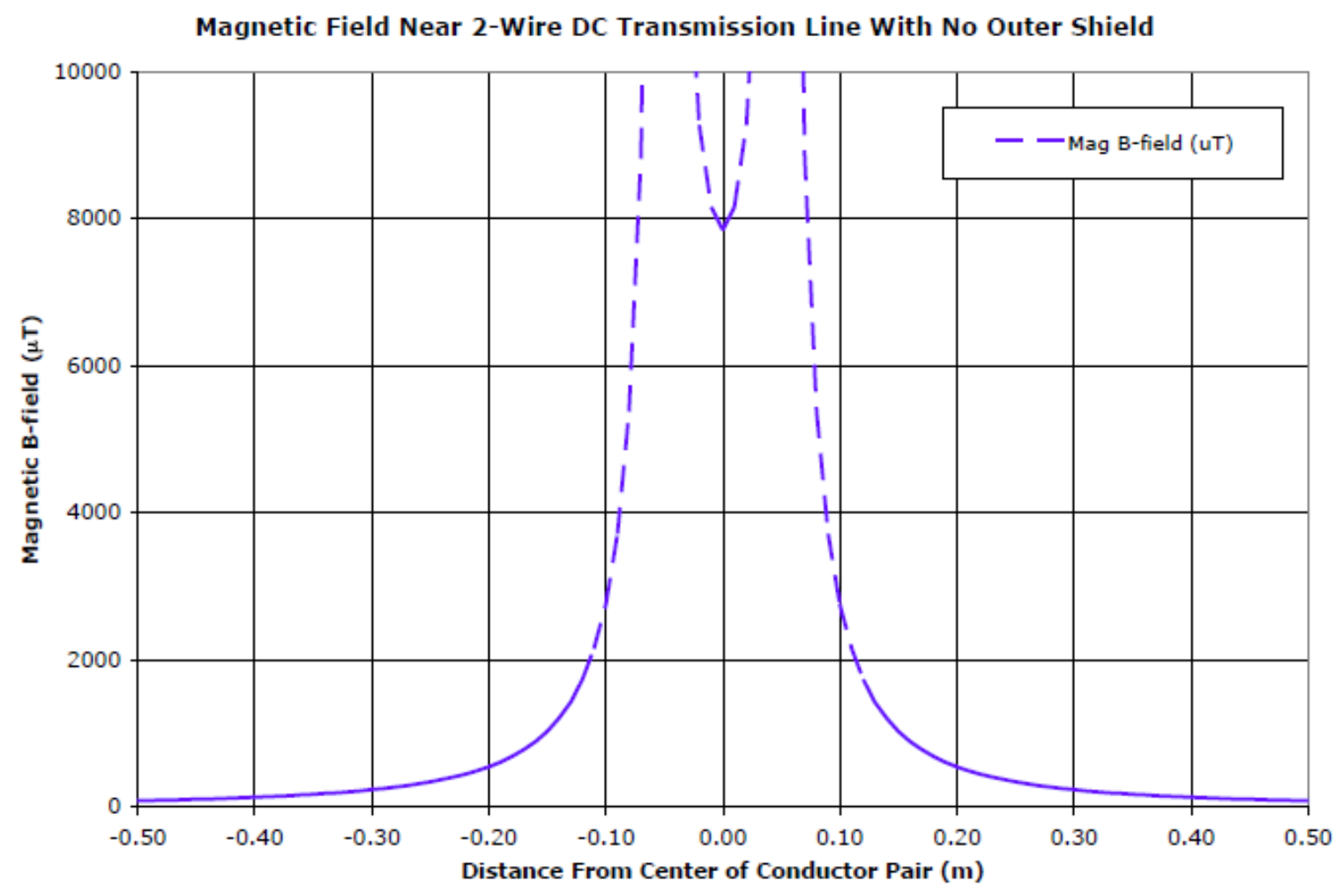

Figure 3. Calculated magnetic field near an unshielded DC electrical transmission line. Source: John Wilgen, Oak Ridge National Laboratory, personal communication.

assembly $( \pm 0.1 \mathrm{~m}$ ) is about $2,000-2,500 \mu \mathrm{T}$. The magnetic field falls off quite quickly, decreasing to less than $100 \mu \mathrm{T}$ at a distance of $0.5 \mathrm{~m}$. An electromagnetically shielded cable with metal braid or armor on the outer surface would have substantially less stray magnetic field outside the surface of the cable assembly.

\section{Static (DC) Magnetic Field Tests}

The exploratory experiments that were carried out in FY 2010 to determine the reactions of common freshwater organisms to elevated magnetic fields were extended in FY 2011 to include fathead minnows (Pimephales promelas), juvenile sunfish (Lepomis spp.), juvenile channel catfish (Ictalurus punctatus), and juvenile striped bass (Morone saxatilis).

Sunfish are abundant sportfish species, widely distributed in the United States, including the large rivers that will support HK development. The striped bass is a commercially and recreationally important species. Being anadromous, striped bass are likely to encounter EMF from marine and hydrokinetic projects in rivers, estuaries, and shallow coastal marine waters. The channel catfish is a common fish species of commercial and recreational value in rivers throughout the United States. As a bottomoriented fish, it is likely to be exposed to EMF from HK projects in rivers, particularly the EMF emitted by 
electrical transmission cables on the riverbed. Although the literature related to electrosensitivity of catfish is sparse, laboratory studies suggest that the brown bullhead (Ameiurus nebulosus) can perceive and orient to low levels of electrical currents in the water (Baranyuk 1981). Similarly low levels of electric current may be used for prey location by the brown bullhead (Peters and van Wijland 1974) and the Amur catfish, Parasilurus asotus (Asano and Hanyu 1986).

Juvenile sunfish (TL ranging from 60 to $82 \mathrm{~mm}$ ), channel catfish (TL ranging from 28 to $42 \mathrm{~mm}$ ) and striped bass (TL ranging from 32 to $45 \mathrm{~mm}$ ) were obtained from the Eagle Bend Fish Hatchery (Tennessee Wildlife Resources Agency) in Clinton, Tennessee. The fish were transported from the hatchery to the laboratory in aerated, insulated coolers and held in stock tanks with water temperature at $25^{\circ} \mathrm{C}$ for at least 3 days before testing.

Experimental procedures - As in FY 2010 (Cada et al. 2011), experiments were carried out to determine whether the fish would be attracted to or repelled by a static magnetic field of the intensity likely to be associated with electrical transmission cables from HK devices. A permanent magnet that was placed under one side of a glass aquarium created a static (DC) magnetic field on one side of the tank that rapidly diminished with distance. We recorded the positions of fish in the magnetized and nonmagnetized (control) tanks at periodic intervals to determine whether the positions and activity levels of the fish in the tanks were affected by the magnetic field.

Test and control tanks were standard glass-sided aquaria, measuring $51 \mathrm{~cm}$ long $\times 26.5 \mathrm{~cm}$ wide $x$ $31.5 \mathrm{~cm}$ tall. A permanent magnet was placed under each of the test tanks by elevating the corners of the tanks with tiles so that the surface of the magnet was close to, but did not touch, the glass bottom of the aquaria. Control tanks (without magnets) were similarly elevated. There were no sediments or other substrate in the glass-bottomed aquaria, but the outside bottom of each tank was covered by opaque paper to prevent the magnet from being seen. De-chlorinated tap water was provided to all holding, test, and control tanks at room temperature $\left(23-25^{\circ} \mathrm{C}\right)$. Lighting throughout the laboratory was provided by overhead fluorescent lights on a daily schedule of 12 hours on and 12 hours off.

The DC (static) magnetic field in each test tank was created by a $10.4 \mathrm{~cm} \times 15.5 \mathrm{~cm} \times 1.3 \mathrm{~cm}$ ceramic (ferrite) bar magnet. The magnetic field was measured with an AlphaLab, Inc. Gaussmeter Model GM-2 (calibrated 5/19/10). On the DC setting, we recorded the Gauss produced by the magnet at various locations in the tank and then converted the readings into $\mu \mathrm{T}$. The magnetic field created by the magnet was strong at the surface of the magnet $(\sim 36,000 \mu \mathrm{T})$ but rapidly decayed with distance (Figure 4$)$. The magnetic field readings on the opposite side of the test tank from the magnet dropped to near background levels within the building (ca 90-190 $\mu \mathrm{T}$ ). The magnetic fields in the control tanks were also at background levels.

Three test tanks and three control tanks were used for testing the effects of EMF exposure on catfish and striped bass. Each experimental treatment consisted of two 46-hour periods with fish in one of the periods exposed to a magnetic field (the treatment) and in the alternate period remaining in the same tank but with no exposure to a magnetic field (the control). For the first 46-hour period, both the tanks with magnets and the side of the tank for placement of a magnet were selected randomly. For the 


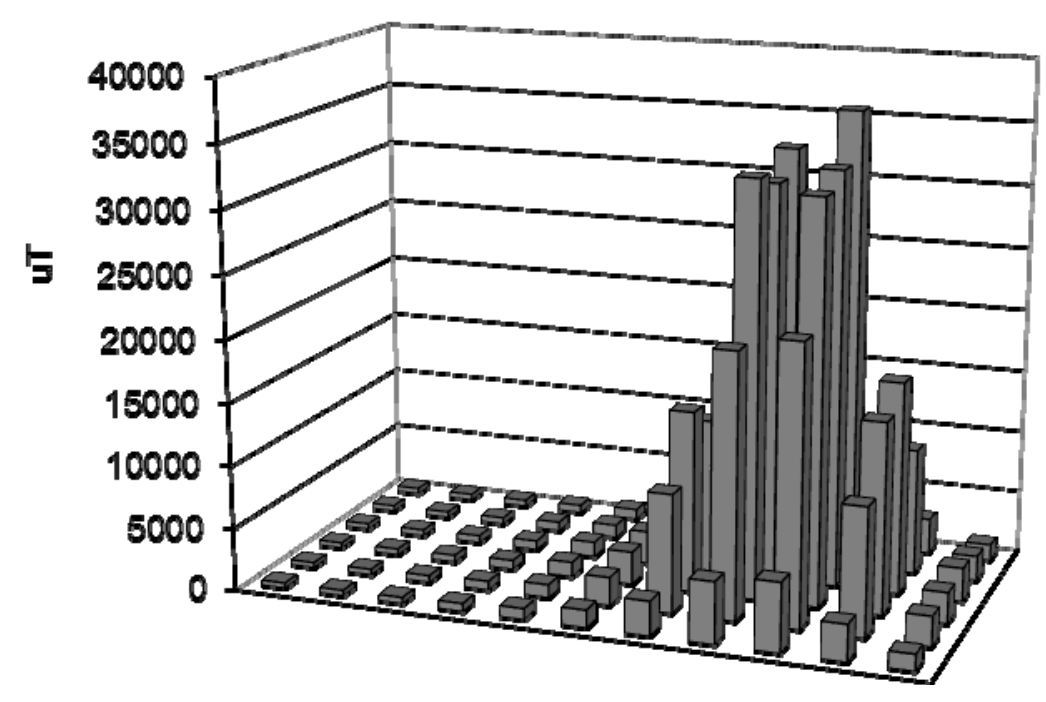

Figure 4. Strength $(\mu \mathrm{T})$ of the static magnetic field created within each aquarium placed over a permanent bar magnet.

The maximum field strength was $36,410 \mu \mathrm{T}$. Measurements were $2 \mathrm{~cm}$ apart.

second 46-hour period, only the side of the tank receiving the magnet was determined randomly. The permanent magnets were placed under glass aquaria and a single channel catfish or striped bass was added to each of the three magnetized (test) tanks and the three non-magnetized (control) tanks. The locations of the fish were periodically recorded. Opaque PVC huts (half-cylinders measuring $7.62 \mathrm{~cm}$ in length and diameter) were placed in the center of each half of the tank to provide cover for the fish (i.e., two huts in each of the six tanks). One of the huts was placed directly over the magnet and the other hut was placed on the opposite side of the tank (Figure 5). The fish were free to move from one hut to the other and select a preferred location. Tops of the aquaria were covered with opaque material and the transparent glass aquaria were placed inside of opaque flumes to minimize disturbance to the fish during the course of the experiment. For each tank, aeration of the water column was provided by constant airflow from an air stone located along the side at mid distance between the two huts to minimize potential influence on a fish moving between huts. The fish were not fed during the 46-hour experiments, but were fed before and between experiments.

The experiments were started in the morning by measuring dissolved oxygen concentrations and temperature for each tank, followed by placing a single fish in each tank without the huts. After the fish had acclimated to their new environments for 55 minutes, the two huts were placed in each tank. Five minutes later we began recording the locations of the fish with video cameras, every 5 minutes for 46 hours. After a 46-hr experiment, magnets were removed from the 3 test tanks, and one of the huts was removed from each test and control tank, with the single remaining hut being placed in the center of each tank. Catfish were then fed granulated fish food, and striped bass fed on defrosted brine shrimp, respectively. After 22 hours we removed unconsumed food and replaced 90 percent of the water volume in each tank. The magnets previously located under the test tanks were placed under the 

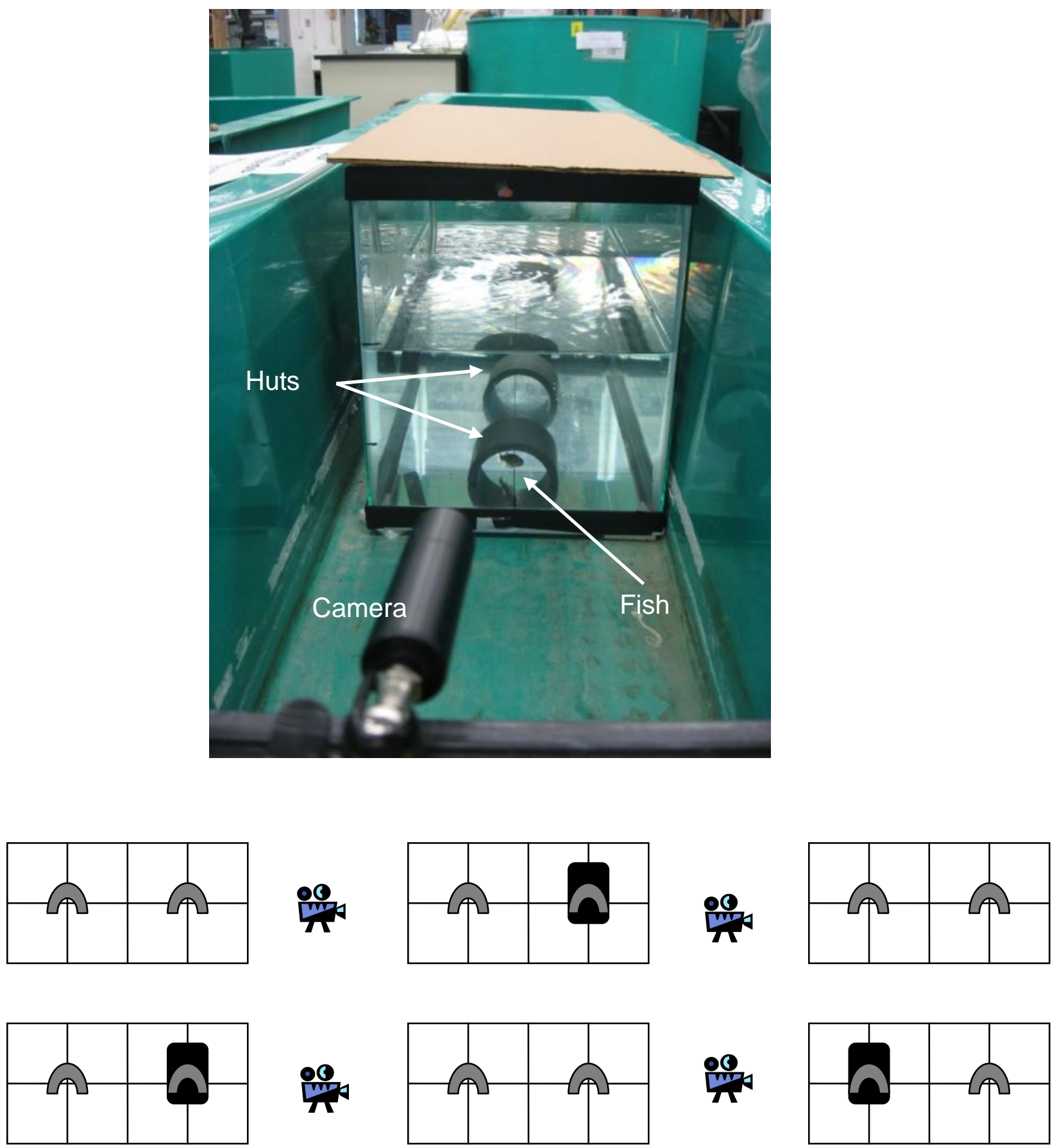

Figure 5. Experimental setup for the static magnetic field (DC) experiments.

The black rectangles represent the placement of the bar magnets relative to the grids on the bottom of the tanks and the grey horseshoes represent the cover structures for fish (opaque PVC "huts"). 
3 control tanks, and another 46-hr experiment was begun. Hence, each fish was exposed to the magnetized (test) and control tanks, and the order of treatments was randomized. For channel catfish and striped bass, a total of twelve fish each were observed during EMF exposure and for the duration of the control treatment without EMF exposure.

Video cameras were set up between the tanks (Figure 5). Using an Image Vault ${ }^{\circledR}$ security system, we recorded the locations of the fish directly from the video images every five minutes between 0620 and 1820 hours, when the room was illuminated by overhead lights. The video images from each test and control tank were examined to determine if the fish were (1) in the hut on the north, (2) out of the hut on the north, (3) in the hut on the south, or (4) out of the hut on the south sides of the test and control tanks.

Data analyses - A Movement Index (MI) was calculated to compare each fish's level of activity in the test and control tanks. The side of the tank the fish occupied was recorded every 5 minutes for the duration of the experiment. The Ml counted the total number of times fish did not occupy the same side of the tank than had been recorded for the previous observation. The MI would be higher for a fish that changed sides frequently (indicating a high level of activity) than for a fish that remained on one side (e.g., inside a hut) for much of the time. The mean values for Movement Indexes of control tanks and treatment (magnetized) tanks were compared with paired t tests adjusted for heteroscedasticity (unequal variance).

For observations from fathead minnows, Chi square tests with Yates correction were performed on individual experiment/tank combinations to determine whether the locations of the fish were different from a uniform distribution, i.e., 50 percent of the observations on each side.

For all four species, paired t tests adjusted for heteroscedasticity compared mean values for occurrences in south or north sides of tanks. Paired t tests were also used to compare mean values for occurrences in the magnet or non-magnet side of tanks.

\section{Variable (AC) Magnetic Field Tests}

We also carried out experiments to detect the reactions of fish to variable magnetic fields that will be produced by HK generators and other AC transforming/transmitting components. A variable magnetic field was created inside a circular test arena using an AC electromagnet, and the behavioral responses of two electrosensitive fish species (paddlefish and lake sturgeon) were video-recorded and quantified. Preliminary tests of the experimental protocol were also carried out using juvenile sunfish (Lepomis spp., TL ranging 5.2 to $9.2 \mathrm{~cm}$ ). Unlike the DC tests, in these $A C$ experiments the EM field was activated instantly with a switch, creating an exposure scenario comparable to a fish drifting down into the field or swimming upstream into the field in a high-velocity riverine environment. Changes in swimming behaviors were recorded and analyzed to ascertain whether the fish were sensitive to the sudden appearance of the EM field.

The paddlefish (Polyodon spathula) is widely distributed throughout the Mississippi River Basin, including slow-flowing water of the Mississippi River and its major tributaries and mainstem reservoirs. 
The paddlefish rostrum is very sensitive to weak electric fields, such as those produced by their planktonic prey, but also by submerged metal rods (Wojtenek et al. 2001; Likens and Hofmann 2007). Thus, paddlefish are likely to encounter HK projects on large rivers in the United States, and because of their electrosensitivity they may be affected by EMF generated by these projects.

The lake sturgeon (Acipenser fulvescens) is found in large lakes and rivers in eastern North America in the upper and middle Mississippi River basin, Great Lakes and Hudson Bay drainages, and upper Coosa River system. This large, bottom-oriented species is likely to be exposed to EMF from HK projects in rivers, particularly the EMF emitted by electrical transmission cables on the riverbed. Sturgeon can utilize electroreceptor senses to locate prey, and may exhibit varying behavior at different electric field frequencies (Basov 1999; 2007). The potential effect of EMF (e.g., altered swimming behavior or ability to find prey) is a concern for this species because it is likely to encounter HK projects and submerged electrical cables during its migration in large rivers.

Juvenile lake sturgeon were obtained from Cohutta fish hatchery, Cohutta, Georgia, on November 11, 2010. They were transported from the hatchery to the laboratory in aerated, insulated coolers and held in stock tanks at $25^{\circ} \mathrm{C}$ prior to testing. At the time of testing, the sturgeon ranged in length from 13.8 to $18.3 \mathrm{~cm}$. Juvenile paddlefish (TL ranging from 25.2 to $30.0 \mathrm{~cm}$ ) were obtained from the Aquila International, Inc. hatchery in Versailles, KY on December 6, 2010. Sturgeon and paddlefish were maintained in separate 500 - $\mathrm{L}$ round fiberglass tanks with dechlorinated freshwater inflow in the Aquatic Ecology Laboratory at Oak Ridge National Laboratory.

Experimental procedures - For the exploratory sunfish tests, a 4-L plastic bucket was filled to a depth of $10 \mathrm{~cm}$ with aerated water. The dissolved oxygen and temperature of the water was measured with a YSI 556 MPS probe. Acceptable ranges for all experiments were a dissolved oxygen concentration of greater than $7 \mathrm{mg} / \mathrm{L}$ and a temperature of $19-25^{\circ} \mathrm{C}$. The bucket was placed inside a $200-\mathrm{L}$ opaque barrel to minimize external disturbances that could cause an unintended startle response. The electromagnet was placed directly underneath the center of the bucket.

A Photron Fastcam PCl camera was suspended above the barrel to capture the actions of fish in the bucket. The camera was held in place with a metal scaffolding. Photron Fastcam Viewer software recorded the video. Experiments were recorded at 250 frames/sec using the "start" trigger mode, with a resolution of $512 \times 480$, default sensitivity, a shutter of 1 frame/sec, and a Gamma level of 1.0. These settings resulted in each video being about 4.3 seconds long. The Gaussmeter was positioned above the bucket so that its display could be seen on the recorded video.

A single sunfish was placed in the bucket and allowed to acclimate for approximately 10 minutes before beginning the trials. Each fish underwent one control trial followed by three experimental trials. During the control trial, the magnet was turned on while unplugged and the fish's response was recorded. This was done to determine if startle responses were caused by the sound or action of the magnet being switched on, rather than the electromagnetic pulse. During the experimental trials, this was repeated with the magnet plugged in. We recorded the fish for 1-2 seconds, then switched the electromagnet on and recorded the fish's response for the remainder of the video. The presence of the magnetic field was 
apparent because the Gaussmeter display would change. We recorded any startle responses and then measured the total length of each fish.

The paddlefish and sturgeon behavior experiments were conducted in an opaque, white cylindrical Nalgene HDPE test tank ( $81 \mathrm{~cm}$ high and $56 \mathrm{~cm}$ in diameter) containing $30 \mathrm{~L}$ of water at a depth of $11 \mathrm{~cm}$ (Figure 6). A round Plexiglas insert in the bottom was marked with a 2-cm grid for swimming speed and distance calculations. A Photron Fastcam PCl (Photron USA, Inc., San Diego, CA) high-speed camera was suspended above the tank and connected to a PC with Photron Fastcam Viewer software for filming. Video analysis was conducted using Visual Fusion software (Boeing-SVS, Inc., Albuquerque, NM). Video files were saved immediately to the PC hard drive and later transferred to an external hard drive for long-term storage.

An AC electromagnet (Magnetech Corp., Novi, MI; model FDE-1) was placed against the outside of the experimental tank at the base, so that the height of the magnet spanned the depth of the water in the tank (see Figure 6). The electromagnet was connected to a variable transformer (Staco Energy Products Co., Dayton, OH; model 3PN1010B) which allowed the size and intensity of the magnetic field to be altered for different treatments. Magnetic field was measured with a Gaussmeter (AlphaLab, Inc., Salt Lake City, UT; model GM-2). The Gaussmeter probe was fixed to the outside of the tank between the tank and the electromagnet, and the meter was affixed to the inside of the tank above water level so that the digital readout was in view of the camera. This allowed the observer to ascertain from the video recording the frame in which the electromagnetic field was activated in the tank, and the frame at which the fish began to respond, if any. The magnetic field was strongest directly over the magnet (approximately $165,780 \mu \mathrm{T}$ ), but decayed rapidly with distance (Figure 7).

Temperature and dissolved oxygen were monitored in the experimental tank prior to each experiment and fresh water was added as needed to match the temperature and DO in the holding tank. Fish were allowed to acclimate to the experimental tank for approximately $15 \mathrm{~min}$ before beginning treatments.

After acclimating to the experimental tank, the fish normally swam in a predictable manner around the outside wall of the circular tank. Watching on the Fastcam Viewer, the observer began a video recording as the fish approached the magnet and then activated the electromagnet with an external switch, just as the fish was swimming over it. A control (non-magnetized) test was carried out in an identical fashion, except that the electromagnet was not plugged into the wall outlet and thus no magnetic field was created. The electromagnet was visible to the observer on camera through the side of the tank, but did not seem to affect the swimming patterns or other behaviors of the fish. The Gaussmeter probe was affixed to the outside of the Nalgene tank so that the fish would not avoid the probe, and therefore the magnet area.

The reactions of an individual fish to the treatment or control exposures were recorded 9 or 10 times, spaced 5 minutes apart. Treatments and controls were randomly assigned. For each video, a total of 1088 frames were recorded at a rate of 250 frames per second, for a total length of approximately $4.3 \mathrm{sec}$. During analysis, the following information was obtained from the video recordings: frame at 


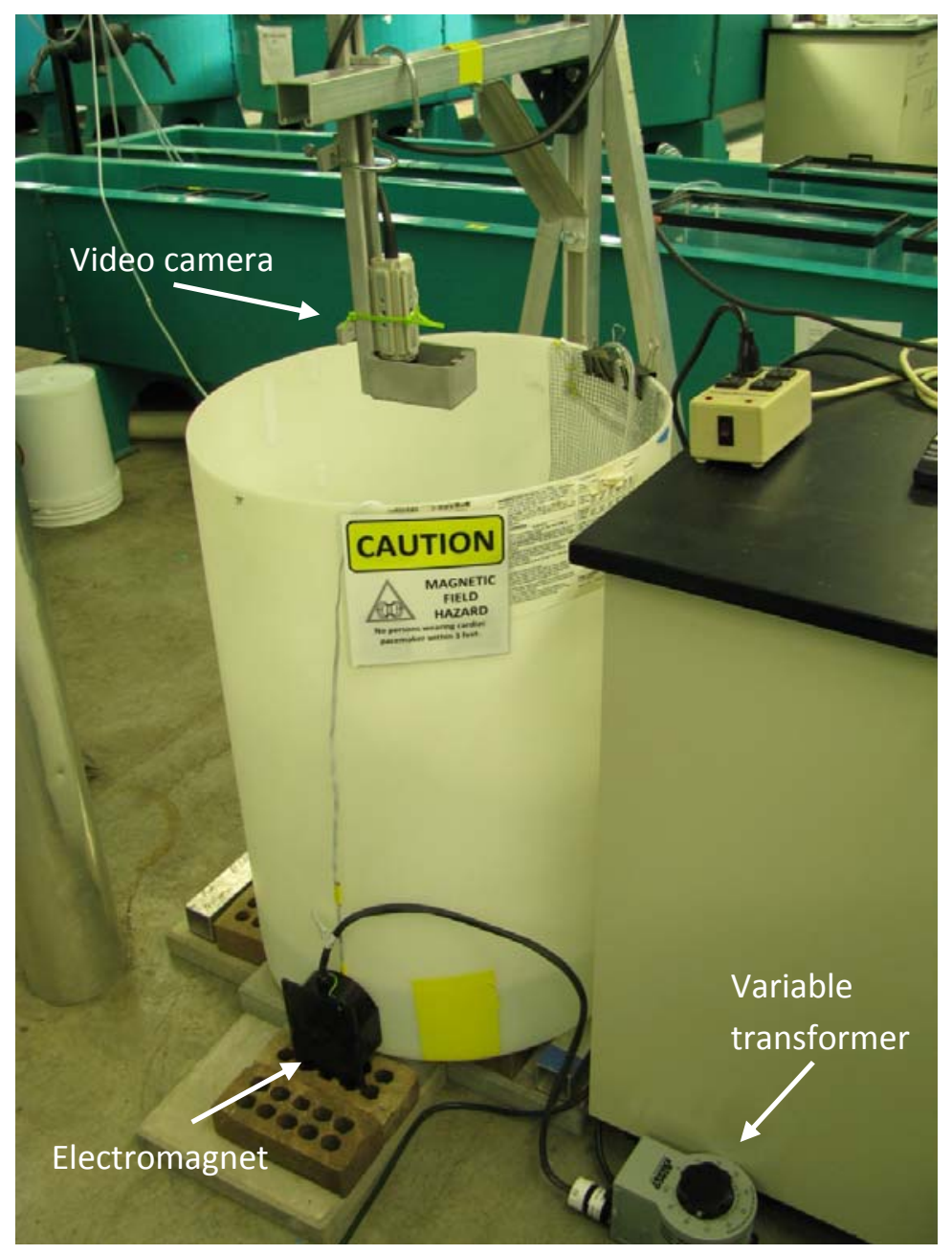

Figure 6. Experimental tank used to test the response of fish to variable magnetic fields created by an AC electromagnet. 

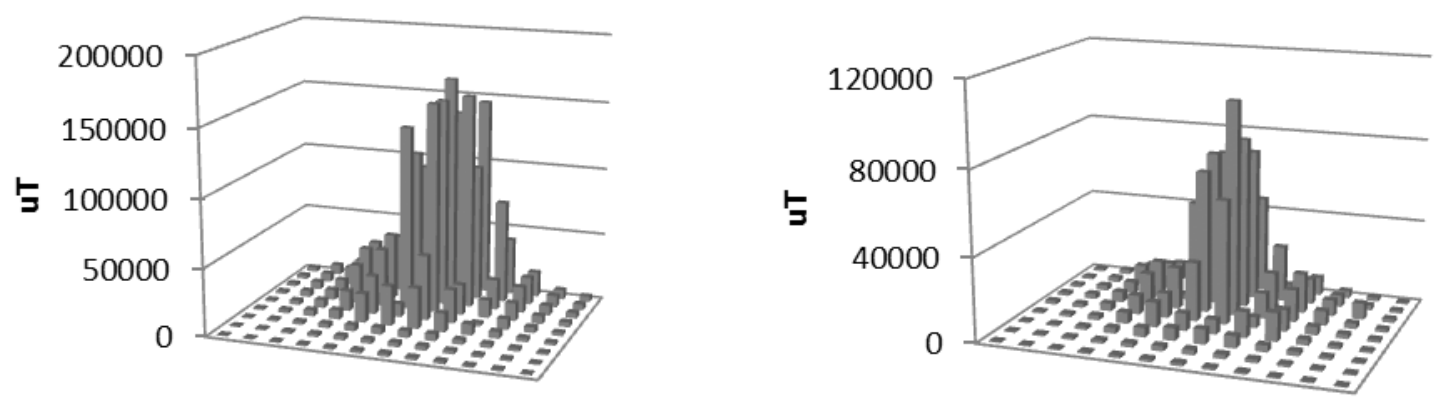

(a)

(b)
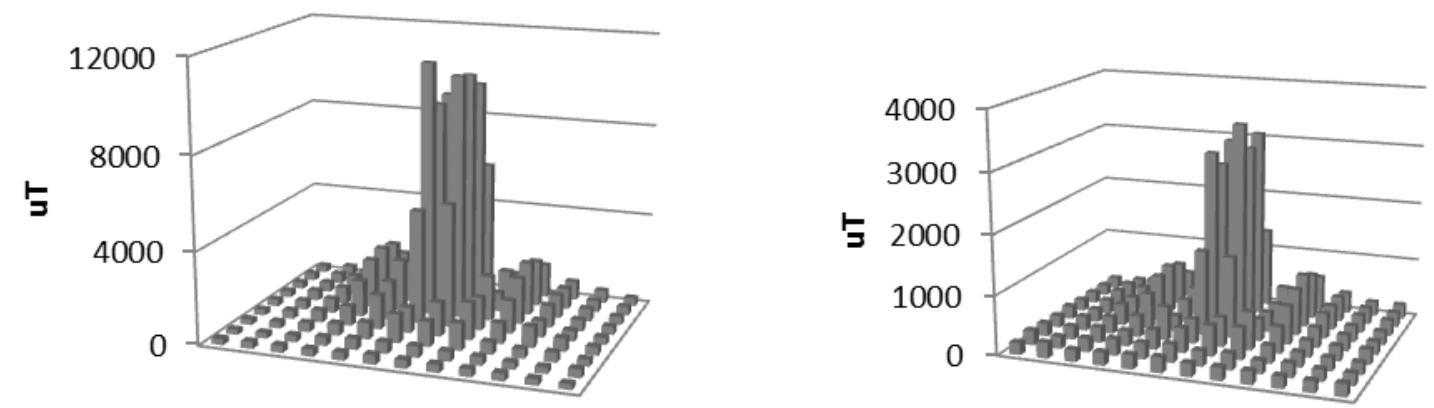

(c)

(d)

Figure 7. Magnetic field produced at the inside wall of an experimental tank by an $\mathrm{AC}$ electromagnet set at four strengths: (a) $100 \%$, (b) $50 \%$, (c) $5 \%$, and (d) $1 \%$.

In all graphs, the far row represents the bottom of the inside of tank; the closest row measurements were taken $17 \mathrm{~cm}$ from bottom of tank, and the field measures $24 \mathrm{~cm}$ wide. Measurements were $2 \mathrm{~cm}$ apart. 
which magnet was turned on, proportion of fish over the magnet when turned on, total duration of reaction by fish, and any altered behaviors that were noted in the recording.

Because some of the behavioral changes that occurred near the electromagnet were subtle (e.g., fin flares or slight acceleration/deceleration), a second observer scored all of the lake sturgeon videos to provide another judgment about whether or not the fish's behavior had changed. The second observer used the same video files and video analysis software as before, and the viewing field was reduced in size so that the observer could not see the screen of the Gaussmeter (and thus did not know whether the recording was from a control or test exposure). The first and second observers agreed on 271 out of 280 video observations of control and test exposures (97\%). Hence, in nearly all cases the changes in sturgeon behaviors (or lack thereof) in the vicinity of the AC electromagnet were clearly distinguishable from normal swimming movements by independent observers.

Data analyses - The durations of reaction (seconds) of test and control fish were compared by means of $\mathrm{t}$ tests and Analysis of Variance (SigmaPlot Version 12; Systat Software, Inc.). Data were first squareroot transformed and tested for normality using the Shapiro-Wilk Normality Test. If the square-root transformed data were non-normal, a Kruskal-Wallis One Way Analysis of Variance on Ranks and Dunnett's test were carried out to compare median values of reaction duration among the groups.

\section{RESULTS}

\section{Static (DC) Magnetic Field Tests}

The following sections describe the Movement Indexes (activity levels) and locations relative to the magnet of the four species of juvenile freshwater fish that were tested in FY 2010-2011.

Fathead minnows - Throughout the experiments, fathead minnows were observed in every location within the tanks, that is, on both magnetized and non-magnetized ends as well as both inside and outside of the huts. The fish changed locations frequently in both the test and control tanks (Figure 8).

Fathead minnows were observed on both the magnetized and non-magnetized sides of the test tanks. Out of 272 observations in each experiment and tank, the fish were recorded on the magnetized side of the test tanks an average of 138 times (51\%). Chi-square tests with Yates correction were performed on individual experiment/tank combinations to determine whether locations were significantly different from a uniform distribution, i.e., 136 (50\%) observations on each side. In some experiment/tank combinations, minnows were recorded at significantly higher percentages on the magnetized side of the tanks ( $P<0.05 ; 3$ out of 12 comparisons). On the other hand, in 4 out of 12 comparisons, significantly higher percentages of minnows were found on the un-magnetized side of the test tanks. In tanks with magnets, 5 of the 12 comparisons and the overall total for the 12 experiment/tank combinations did not show statistically significant differences in location over the course of the 46-hour experiments (Table 1). Owing to the frequent movements and uniform distribution of fish, there was no indication that fathead minnow were either attracted to or repelled by the static magnetic field. 


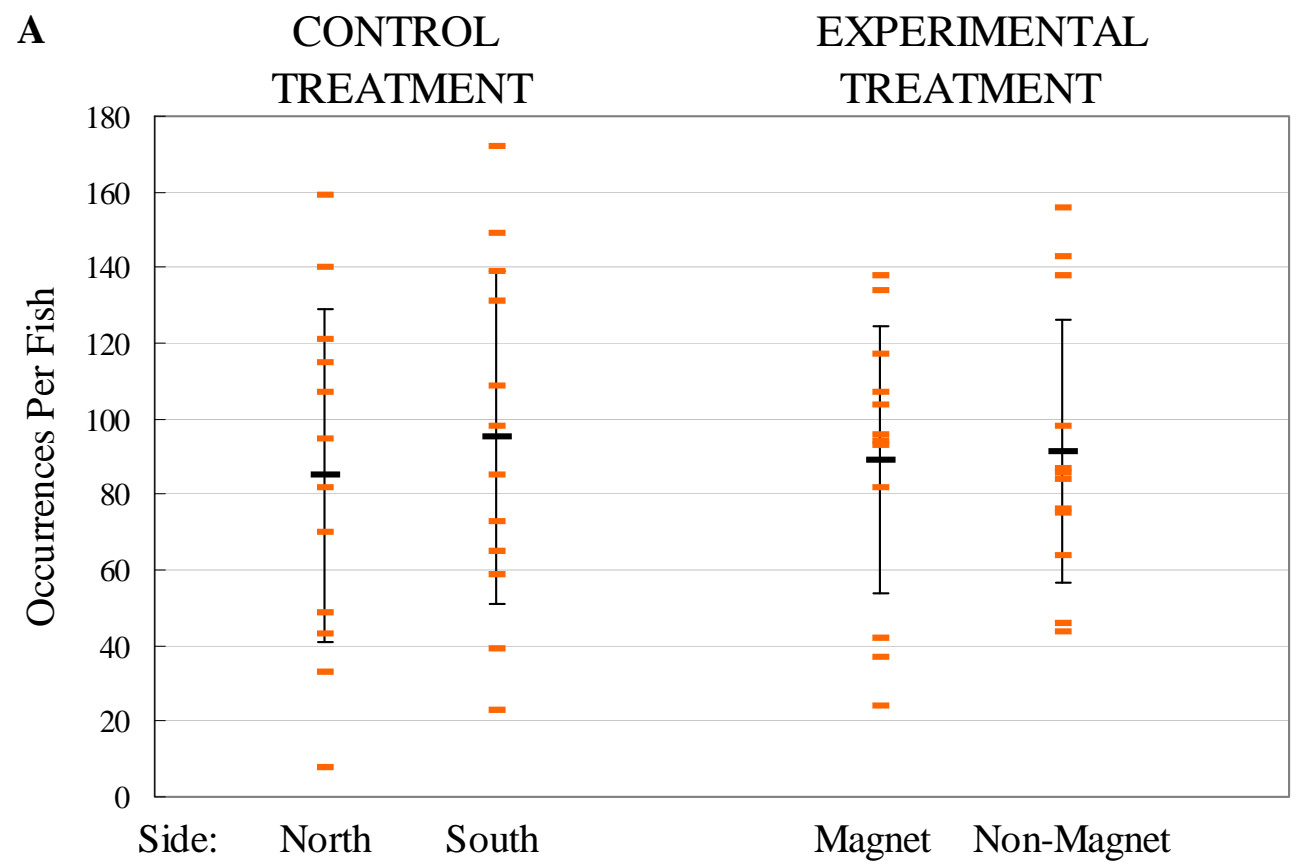

B

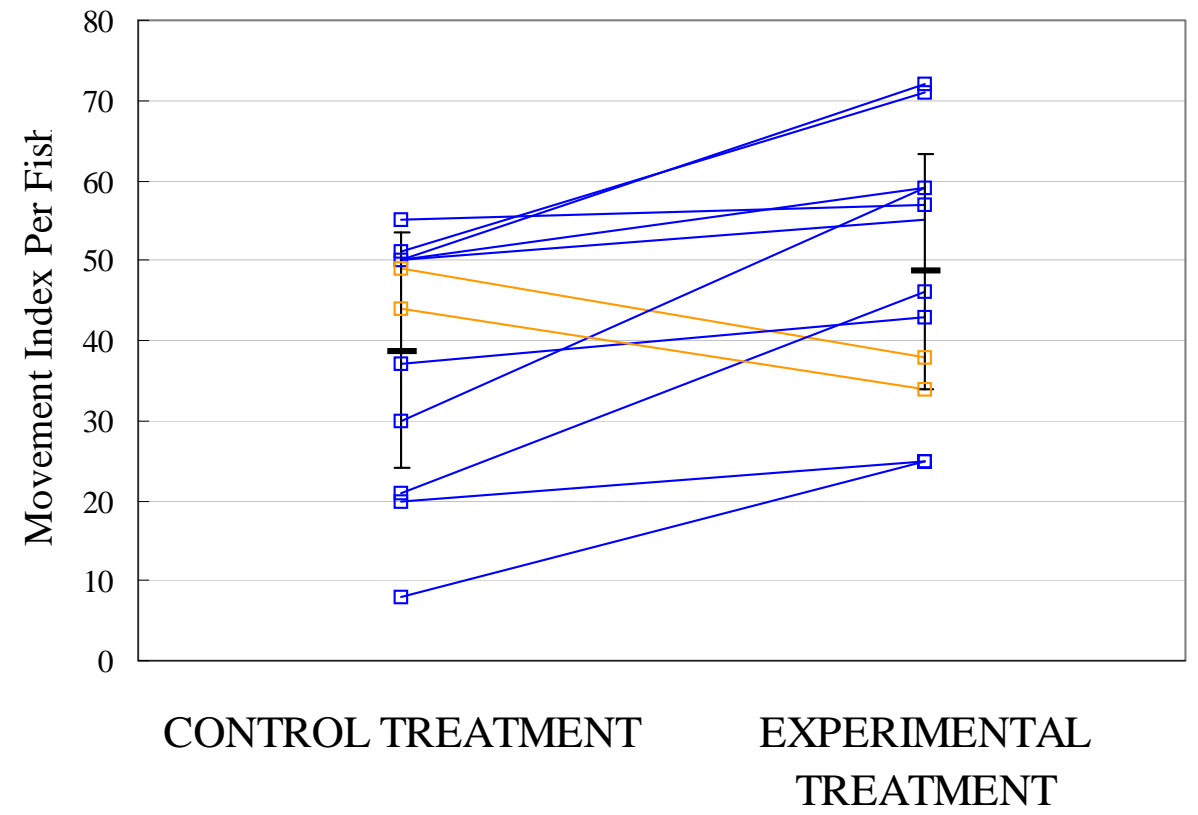

Figure 8. (A) Occurrences (total number of observations) of individual fathead minnows (red lines) on the north and south sides (control treatments) and on the magnetized and non-magnetized sides

(experimental treatments). Black lines represent the mean \pm 1 SD. (B) The Movement indexes (MI) for each fish during control and experimental treatments are paired. Blue lines indicate experimental treatment $\mathrm{MI}$ was greater than control treatment movement index; red lines indicate control treatment MI was greater. Black lines represent mean \pm 1 SD. 
Table 1. Locations of individual fathead minnows during static magnetic field exposure experiments.

Values are the number of observations (made at 5-minute intervals) of fish locations during the 46-hour-long experiment. Control tanks were divided into North $(\mathrm{N})$ and South $(\mathrm{S})$ halves. Test tanks were divided into magnetized $(\mathrm{M})$ and un-magnetized $(\mathrm{U})$ halves. $P$ values are the probabilities that the minnows preferred the $\mathrm{N}$ side of the tank over the $\mathrm{S}$ side or the $\mathrm{M}$ side of the tank over the $\mathrm{U}$ side.

\begin{tabular}{|c|c|c|c|c|c|c|c|c|c|c|c|c|}
\hline \multirow[b]{2}{*}{$\begin{array}{c}\text { Experiment } \\
\text { Number }\end{array}$} & \multicolumn{6}{|c|}{ CONTROL TANKS (WITHOUT MAGNETS) } & \multicolumn{6}{|c|}{ TEST TANKS (WITH MAGNETS) } \\
\hline & $\begin{array}{c}\text { Tank } \\
\text { Number }\end{array}$ & $\begin{array}{l}\text { Inside } \\
\text { Hut N }\end{array}$ & $\begin{array}{c}\text { Outside } \\
\text { Hut N }\end{array}$ & $\begin{array}{l}\text { Inside } \\
\text { Hut S }\end{array}$ & $\begin{array}{c}\text { Outside } \\
\text { Hut S }\end{array}$ & $\begin{array}{l}\text { P Value } \\
\text { (N vs. S) }\end{array}$ & $\begin{array}{c}\text { Tank } \\
\text { Number }\end{array}$ & $\begin{array}{l}\text { Inside } \\
\text { Hut M }\end{array}$ & $\begin{array}{c}\text { Outside } \\
\text { Hut M }\end{array}$ & $\begin{array}{l}\text { Inside } \\
\text { Hut U }\end{array}$ & $\begin{array}{l}\text { Outside } \\
\text { Hut U }\end{array}$ & $\begin{array}{l}\text { P Value } \\
\text { (M vs. U) }\end{array}$ \\
\hline \multirow{2}{*}{1} & 1 & 198 & 31 & 15 & 28 & $<0.01$ & 2 & 147 & 52 & 35 & 38 & $<0.01$ \\
\hline & 6 & 21 & 103 & 24 & 124 & 0.34 & 7 & 260 & 4 & 8 & 0 & $<0.01$ \\
\hline 2 & 1 & 116 & 67 & 17 & 72 & $<0.01$ & 2 & 204 & 12 & 47 & 9 & $<0.01$ \\
\hline \multirow{3}{*}{3} & 2 & 186 & 2 & 58 & 26 & $<0.01$ & 1 & 51 & 62 & 16 & 143 & 0.06 \\
\hline & 5 & 77 & 52 & 88 & 55 & 0.61 & 3 & 36 & 69 & 28 & 139 & $<0.01$ \\
\hline & 7 & 96 & 42 & 44 & 90 & 0.93 & 6 & 38 & 78 & 51 & 105 & 0.10 \\
\hline 4 & 2 & 195 & 18 & 48 & 11 & $<0.01$ & 1 & 21 & 29 & 126 & 96 & $<0.01$ \\
\hline $\begin{array}{l}\text { Average } \\
\text { number of } \\
\text { observations }\end{array}$ & & 104 & 57 & 47 & 65 & & & 84 & 54 & 60 & 74 & \\
\hline
\end{tabular}


We compared the number of observations of fathead minnows inside of the huts and outside of the huts (Table 1). Out of 272 observations in each experiment and tank, fish were recorded inside the huts on an average of 151 times (56\%) for control tanks and 144 times (53\%) for test tanks. There was no indication that the presence of the static magnetic field caused the fathead minnows to either seek or avoid shelter in the huts.

Movement indices for fathead minnows were significantly greater $(P<0.05)$ in the magnetized treatments than in the controls. This finding suggests that fathead minnow activity levels were increased in the presence of the magnet, although there was no indication of attraction or avoidance of the field.

Sunfish - Sunfish spent about equal amounts of time on each side of the tank during both control and magnetized treatments (Figure 9). The proportion of times spent in the magnetized and nonmagnetized sections of the test tanks were not significantly different from each other or from a value of $0.5(P<0.05)$. Similarly, the proportion of time spent in the north and south sides of the control tanks were not significantly different.

Differences between magnetized and control treatments in the movement indexes for sunfish were not significantly different $(P<0.05)$, suggesting that activity levels were not affected by the static magnetic field.

Striped bass - Striped bass were the most active species examined and were rarely observed in huts, independent of placement in a treatment or control tank. Striped bass spent about equal amounts of time on each side of the tank during both control and magnetized treatments (Figure 10). No statistically significant difference was found in proportion of times spent in the magnetized and nonmagnetized sections of the test tanks. Similarly, the proportions of time spent in the north and south sides of the control tanks were not significantly different. Although activity levels varied among individuals, movement index values for striped bass in magnetized tanks were not significantly different from values obtained during control treatments.

Channel catfish - Channel catfish were observed in every location within the tanks, that is, on both magnetized and non-magnetized side of test tanks (or North and South sides of control tanks), as well as both inside and outside of the huts. Although movement index values from treatment and control tanks were lower than observed for other species, channel catfish did change locations frequently in both the test and control tanks (Figure 11).

Channel catfish in the test tanks (with magnets) spent considerable amounts of time both inside and outside of the huts (Figure 12). Out of 281 observations in each experiment and tank combination, fish were found inside the huts on an average of 179 times (63.5\%) for control tanks and an average of 197 times (69.9 \%) for test tanks. No statistically significant differences were found in proportion of times spent in the magnetized and non-magnetized sections of the test tanks. Similarly, the proportions of time spent in the north and south sides of the control tanks were not significantly different. There was no indication that the presence of the static magnetic field caused the channel catfish to either seek 


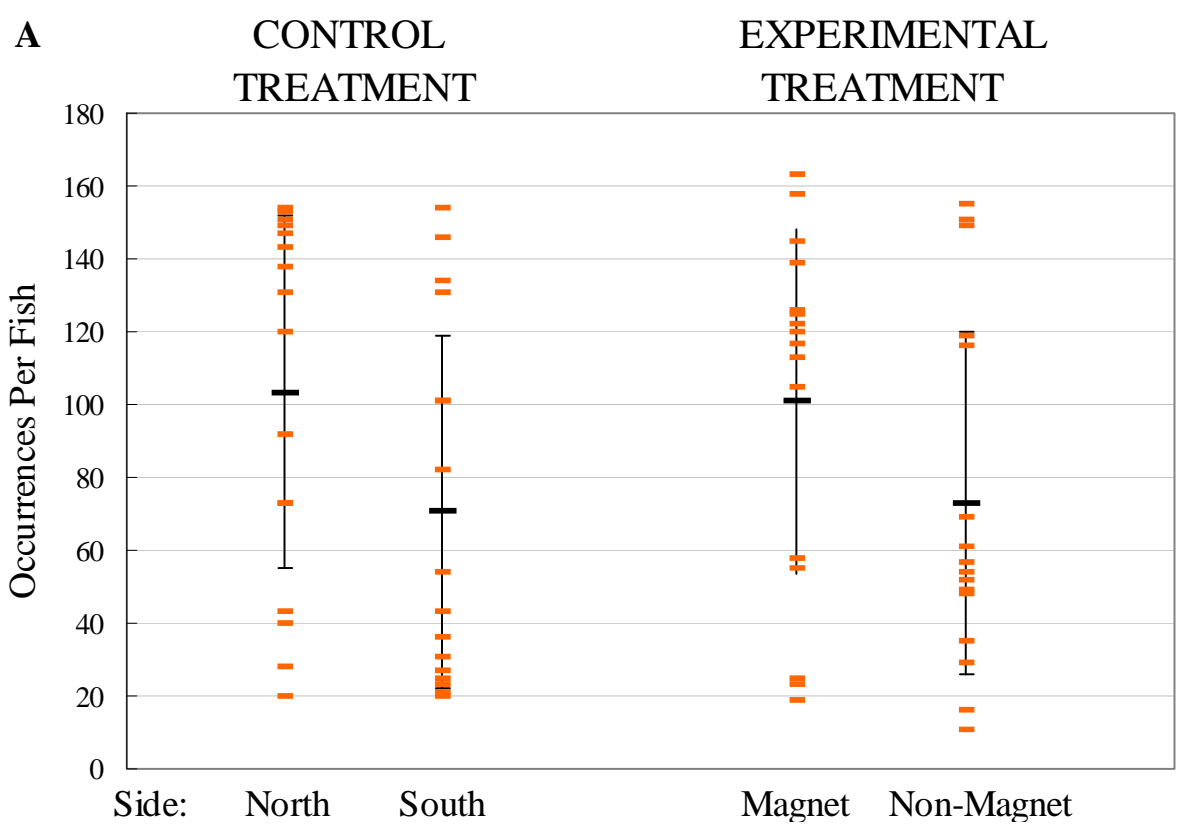

B

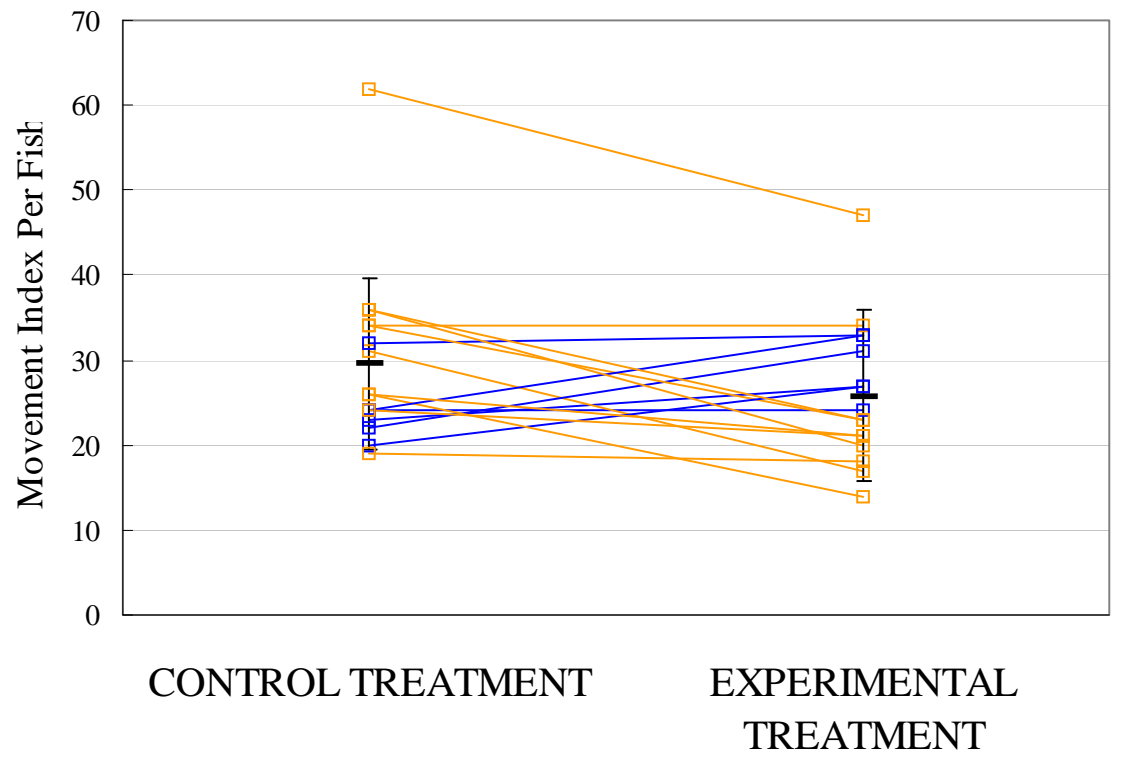

Figure 9. (A) Occurrences (total number of observations) of individual sunfish (red lines) on the north and south sides (control treatments) and on the magnetized and non-magnetized sides (experimental treatments). Black lines represent the mean \pm 1 SD. (B) The Movement indexes (MI) for each fish during control and experimental treatments are paired. Blue lines indicate experimental treatment MI was greater than control treatment MI; red lines indicate control treatment $\mathrm{MI}$ was greater. Black lines represent mean $\pm 1 \mathrm{SD}$. 


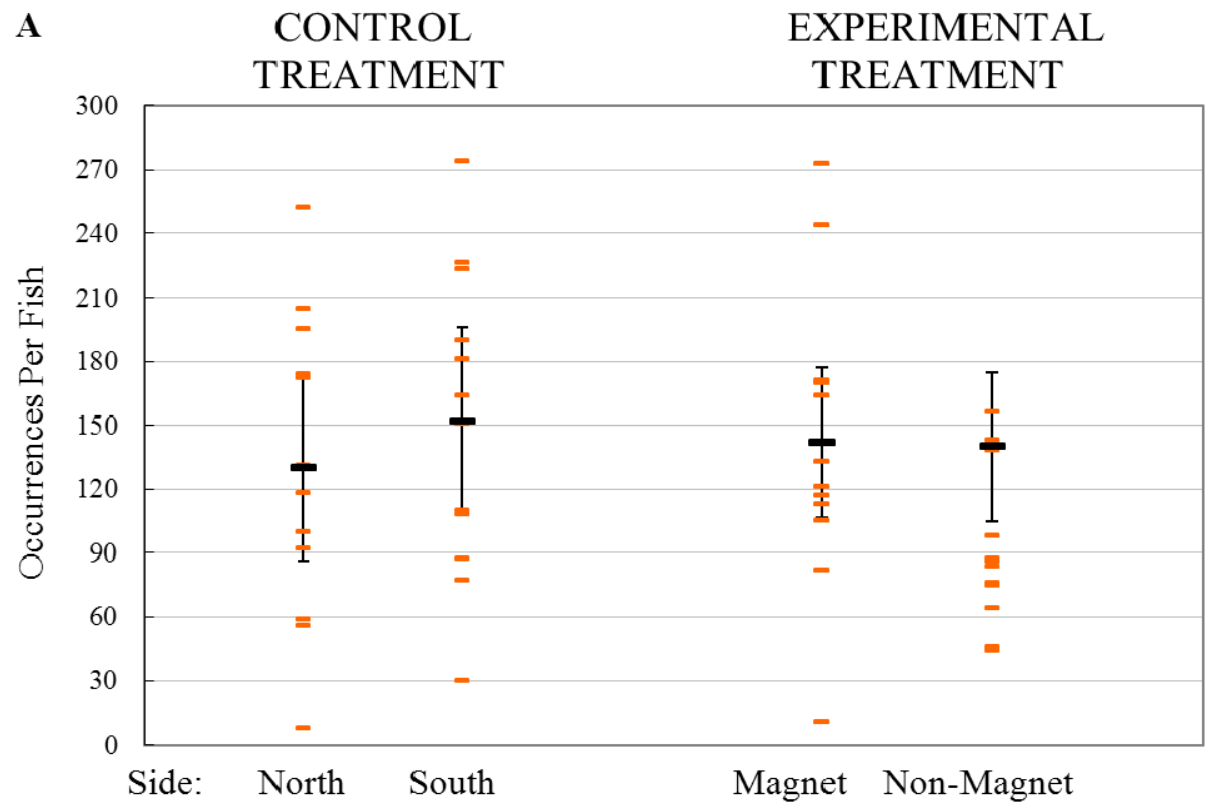

B

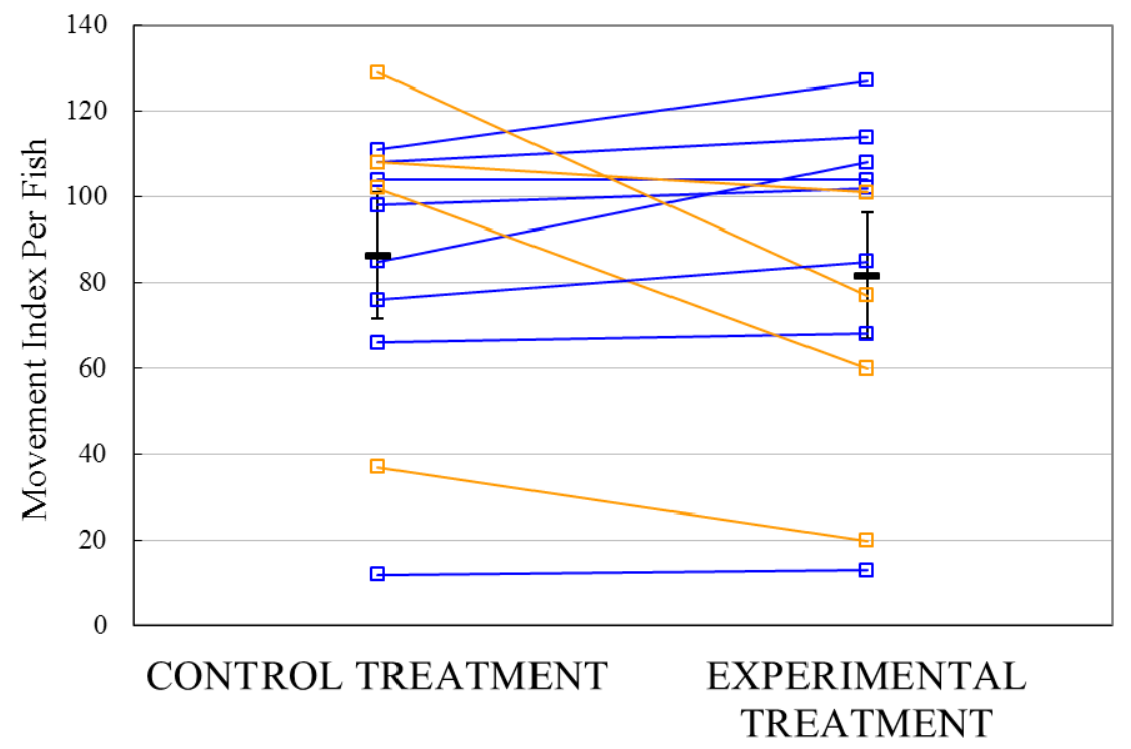

Figure 10. (A) Occurrences (total number of observations) of individual striped bass (red lines) on the north and south sides (control treatments) and on the magnetized and non-magnetized sides (experimental treatments). Black lines represent the mean \pm 1 SD. (B) The Movement Indexes (MI) for each fish during control and experimental treatments are paired. Blue lines indicate experimental treatment $\mathrm{MI}$ was greater than control treatment $\mathrm{MI}$; red lines indicate control treatment $\mathrm{MI}$ was greater. Black lines represent mean \pm 1 SD. 


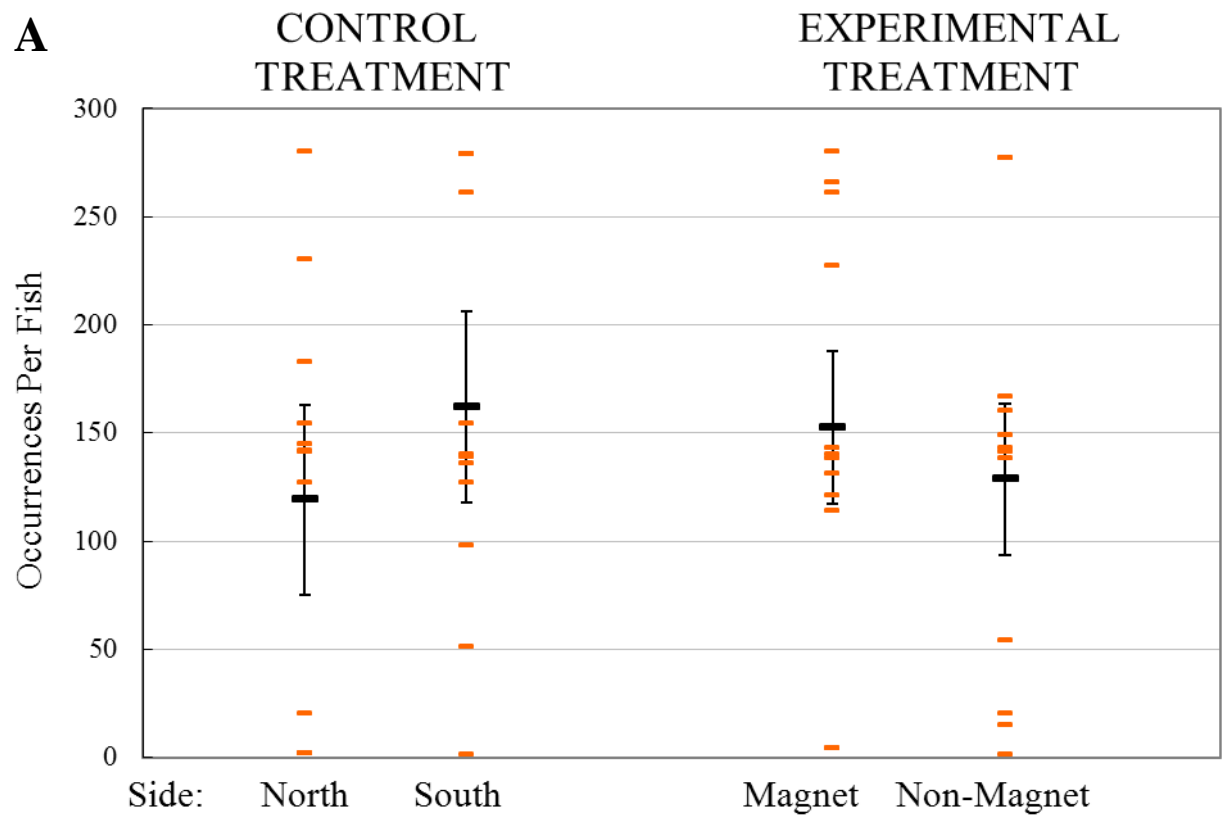

B

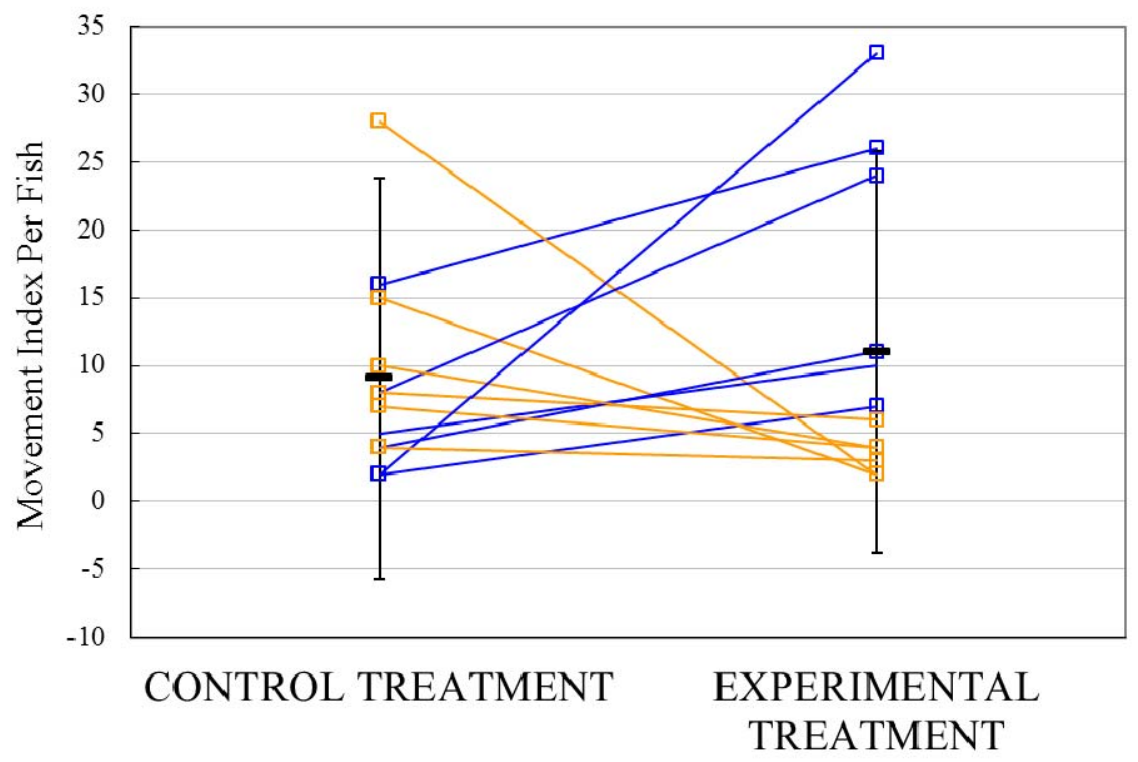

Figure 11. (A) Occurrences (total number of observations) of individual catfish (red lines) on the north and south sides (control treatments) and on the magnetized and non-magnetized sides (experimental treatments). Black lines represent the mean \pm 1 SD. (B) The Movement Indexes (MI) for each fish during control and experimental treatments are paired. Blue lines indicate experimental treatment $\mathrm{MI}$ was greater than control treatment $\mathrm{MI}$; red lines indicate control treatment $\mathrm{MI}$ was greater.

Black lines represent mean \pm 1 SD. 


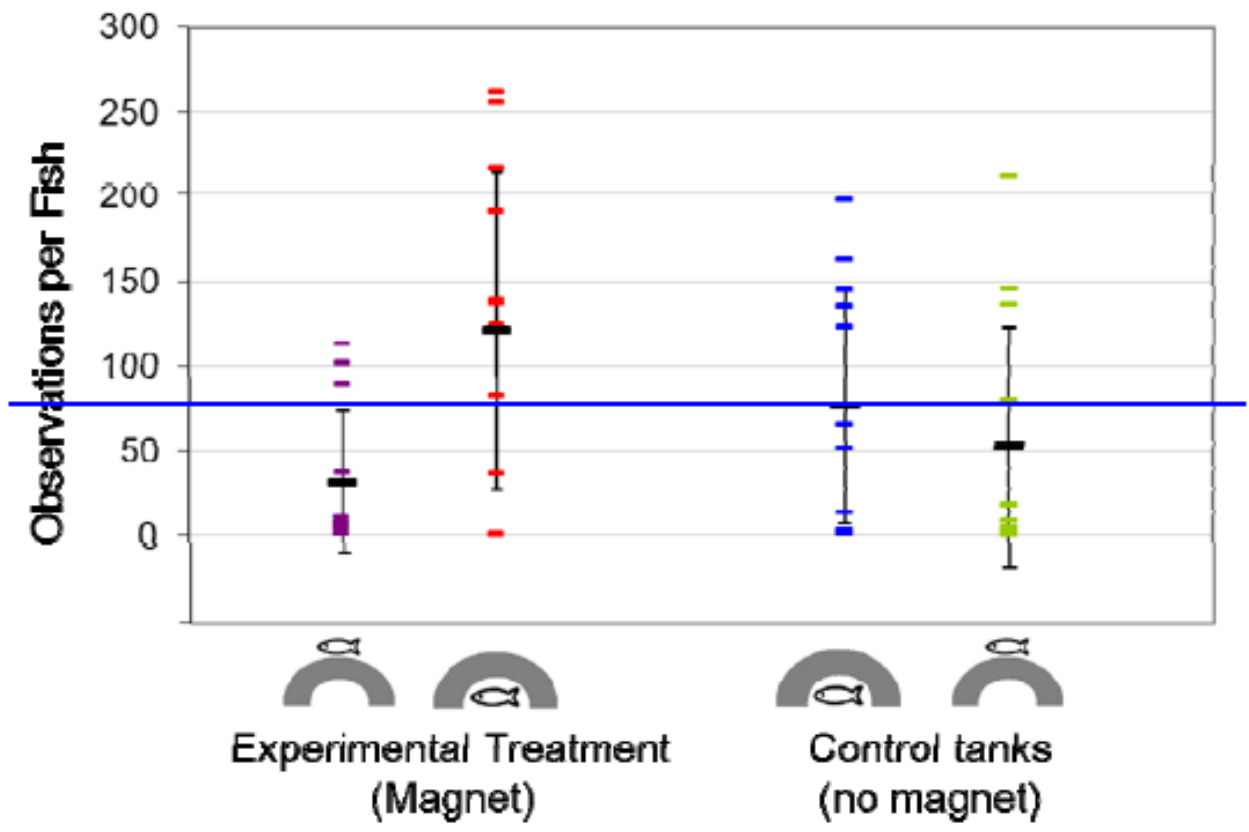

Figure 12. Occurences (total number of observations) of individual channel catfish $(n=12)$ inside and outside of huts from treatment tanks for sides with a magnet and sides without a magnet.

or avoid shelter in the huts. Owing to the frequent movements, lack of a consistent preference for magnetized or non-magnetized sides, and an overall variable distribution of the fish occurrence counts we found no indication that channel catfish were either attracted to or repelled by the static magnetic fields in these tests.

From the four species examined, only fathead minnows showed a statistically significant $(\alpha=0.5$, $p<0.025$ ) difference in activity levels; values for movement index were slightly larger for fathead minnows exposed to magnetized tanks compared to values from fathead minnows in control treatments.

\section{Variable (AC) Magnetic Field Tests}

The results of preliminary tests of sunfish responses to the AC electromagnet are shown in Table 2. Few startle responses were observed, even when the sunfish were exposed to a variable magnetic field strength of as much as $124,000 \mu \mathrm{T}$. Five out of 15 sunfish exhibited a startle response in one of the tests (usually a C-start reaction); 4 of these reactions occurred during a treatment and one occurred during the control (Table 2). 
Table 2. Behavioral responses of juvenile sunfish (Lepomis spp.)

to a strong variable (AC-generated) electromagnetic pulse. Maximum value of the field was approximately $124,000 \mu \mathrm{T}$. A dash indicates no response.

\begin{tabular}{cccccc} 
& & \multicolumn{3}{c}{ EXPOSURE TO VARIABLE ELECTROMAGNETIC PULSE } \\
\cline { 3 - 5 } Fish & Control & \multicolumn{2}{c}{ Trial 1 } & Trial 2 & Trial 3 \\
\hline 1 & - & - & - & - \\
2 & - & - & - & - \\
3 & - & - & - & - \\
4 & - & - & - & - \\
5 & - & Startle & - & - \\
6 & - & - & - & Weak C-start \\
7 & - & - & - & - \\
8 & - & - & Weak C-start & - \\
9 & - & Weak C-start & - & - \\
10 & - & - & - & - \\
11 & - & - & - & - \\
12 & Weak C-start & - & - & - \\
13 & - & - & - & - \\
14 & - & - & - & - \\
15 & - & - & - & - \\
\hline
\end{tabular}

The magnetic fields created by the AC electromagnet in the paddlefish and sturgeon tests are shown in Figure 7. The maximum value of the field at full power was approximately $165,780 \mu \mathrm{T}$ (Figure $7 \mathrm{a}$ ); the strength of the field decreased rapidly in both horizontal and vertical directions from the peak value, such that such that background levels were measured approximately $28 \mathrm{~cm}$ away from the wall, or about halfway across the tank. Normal background levels in the laboratory where these experiments were conducted were approximately 100-200 $\mu \mathrm{T}$. Also, the strength of the magnetic field decreased proportionally to the percent of power applied to the electromagnet by the variable transformer. The maximum value of the field at 50\% power was approximately 103,020 $\mu \mathrm{T}$ (Figure 7b); background levels were measured $19 \mathrm{~cm}$ away from the tank wall. At $5 \%$ field strength, the maximum value was approximately 11,030 $\mu \mathrm{T}$ (Figure 7c), and background levels were measured at approximately $10 \mathrm{~cm}$ away from the tank wall. Finally, at $1 \%$ field strength, the maximum value was approximately $3,510 \mu \mathrm{T}$ (Figure 7d), and background levels were measured at approximately $5 \mathrm{~cm}$ away from the wall of the tank.

Table 3 describes the swimming behaviors exhibited by the paddlefish and lake sturgeon in the video recordings. The behaviors of "swimming normally" (behavior \#1 in Table 3) and "leaving the area of the magnet" (\#13) were considered to be normal behaviors for lake sturgeon and paddlefish, and were observed during some part of nearly every video recording for the treatment and control exposures; behaviors (1) and (13) were recorded for $96.0 \%$ and $83.9 \%$ of the frames, respectively. Departures from normal swimming behavior were quantified and considered to reflect attraction to the stimulus (behaviors 2, 3, and 12) or avoidance of the stimulus (behaviors 4, 6, and 10). Startle-type behaviors 5 , $7,8,9$, and 11 demonstrated that the fish was able to sense the sudden appearance of the field, but did not indicate whether there was an attraction or avoidance reaction. 


\section{Table 3. Summary of paddlefish and lake sturgeon behaviors observed}

following exposure to variable (AC) magnetic fields.

1. Normal Swimming

2. Speed slows/gliding

3. Sudden stop over magnet

4. Speed increases

5. C-shape without escape

6. C-shape with escape

7. Body spasm

8. Thrashing

9. Tail shake/spasm

10. "Jumps" away

11. Pectoral fin flare

12. Stays in area of magnet

13. Leaves area of magnet
No change from normal swimming (varies by species)

Stops actively propelling body forward but still moving forward

No movement; stops directly over stimulus area

Fish exhibits burst swimming or gradual acceleration

Forms C-shape but does not use it to leave area of the magnet

Forms C-shape and leaves the area of the magnet

Entire body shakes/quivers

More pronounced than spasm; shaking, often breaking surface/splashing

Only tail exhibits spasms described above

Entire body moves away from stimulus area without being propelled by fins; looks like a vertical hop or jump

Pectoral fins are extended wider

Does not leave stimulus area

Swims away from magnetized area at usual speed and direction

Paddlefish juveniles showed very little reaction to the variable magnetic field. Out of 100 observations, $8 \%$ exhibited some altered behavior when the electromagnet was activated. The most common paddlefish responses to the EMF were formation of a C-shape or thrashing, but these behaviors were also observed in $2 \%$ of the control trials (Table 4). The differences in duration of reaction between the test and control groups were not great enough to exclude the possibility that the difference is due to random sampling variability; that is, the differences were not statistically significant $(P=0.169)$.

Lake sturgeon juveniles, on the other hand, showed a variety of reactive behaviors to the magnet, with $96 \%$ of fish reacting in some way to the electromagnet at full power (Table 4). At a reduced field strength, lake sturgeon again showed a variety of behaviors; $100 \%$ of fish showed some reaction at both $25 \%$ and $50 \%$ of full power (Figure 13). When magnetic field strength was reduced further, reaction rates dropped slightly; $47 \%$ of the sturgeon reacted at $4 \%$ of full power and $60 \%$ reacted at $5 \%$ of full power. When the power of the electromagnet was reduced to $1 \%$ (maximum magnetic field strength of $3,510 \mu \mathrm{T}), 1$ of 15 experimental exposures $(7 \%)$ resulted in altered swimming behaviors. All of the 
Table 4. Summary of experiments and reactions of fish following exposure to a variable (AC-generated) electromagnetic field.

\begin{tabular}{|c|c|c|c|c|c|c|c|c|c|c|c|c|c|c|c|c|c|c|c|c|}
\hline \multicolumn{6}{|c|}{ EXPERIMENTAL CONDITIONS } & \multicolumn{15}{|c|}{$\begin{array}{c}\text { Altered BeHAVIORS ObSERVED } \\
\text { (SEe TABLE } 2 \text { FOR DEFINITION OF THE NUMERIC CODES) }\end{array}$} \\
\hline $\begin{array}{c}\text { Experiment } \\
\text { Number }\end{array}$ & Species & $\begin{array}{c}\text { Number } \\
\text { of Fish }\end{array}$ & $\begin{array}{c}\text { Total } \\
\text { Observations } \\
\text { per Fish }\end{array}$ & $\begin{array}{c}\text { Observations } \\
\text { per Fish per } \\
\text { Treatment } \\
\end{array}$ & $\begin{array}{c}\text { Percent of } \\
\text { Maximum } \\
\text { Magnetic } \\
\text { Field }\end{array}$ & $\begin{array}{c}\text { Number of } \\
\text { Observations }\end{array}$ & $\begin{array}{c}\begin{array}{c}\text { Number } \\
\text { of } \\
\text { Reactions }\end{array} \\
\end{array}$ & $\begin{array}{c}\text { Percent of } \\
\text { Observations } \\
\text { in which Fish } \\
\text { Reacted }\end{array}$ & $\begin{array}{c}\text { Mean } \\
\text { Duration of } \\
\text { Reaction (S) }\end{array}$ & 2 & 3 & 4 & 5 & 6 & 7 & 8 & 9 & 10 & 11 & 12 \\
\hline PF1 & P. spathula & 10 & 10 & 5 & $\begin{array}{c}100 \\
0\end{array}$ & $\begin{array}{l}50 \\
50\end{array}$ & $\begin{array}{l}4 \\
1\end{array}$ & $\begin{array}{l}8 \\
2\end{array}$ & $\begin{array}{l}1.66 \\
0.46\end{array}$ & & & & $\begin{array}{l}2 \\
1\end{array}$ & 1 & & $\begin{array}{l}3 \\
1\end{array}$ & & 1 & & $\begin{array}{l}6 \\
5\end{array}$ \\
\hline LS1 & A. fulvescens & 10 & 10 & 5 & $\begin{array}{c}100 \\
0\end{array}$ & $\begin{array}{l}50 \\
50\end{array}$ & $\begin{array}{c}48 \\
4\end{array}$ & $\begin{array}{c}98 \\
8\end{array}$ & $\begin{array}{l}1.86 \\
0.18\end{array}$ & $\begin{array}{c}29 \\
4\end{array}$ & 17 & & $\begin{array}{c}10 \\
1\end{array}$ & 4 & $\begin{array}{c}22 \\
1\end{array}$ & 9 & 8 & 6 & 36 & $\begin{array}{c}18 \\
1\end{array}$ \\
\hline LS2 & A. fulvescens & 10 & 9 & 3 & $\begin{array}{c}25 \\
50 \\
0\end{array}$ & $\begin{array}{l}30 \\
30 \\
30\end{array}$ & $\begin{array}{c}30 \\
30 \\
5\end{array}$ & $\begin{array}{c}100 \\
100 \\
17\end{array}$ & $\begin{array}{l}2.03 \\
1.95 \\
1.09\end{array}$ & $\begin{array}{c}17 \\
15 \\
2\end{array}$ & $\begin{array}{l}12 \\
13\end{array}$ & 1 & $\begin{array}{l}5 \\
5 \\
1\end{array}$ & 2 & $\begin{array}{c}17 \\
21 \\
2\end{array}$ & $\begin{array}{l}4 \\
5\end{array}$ & 2 & $\begin{array}{l}9 \\
8 \\
1\end{array}$ & $\begin{array}{c}23 \\
26 \\
2\end{array}$ & $\begin{array}{c}12 \\
8 \\
1\end{array}$ \\
\hline LS3 & A. fulvescens & 5 & 9 & 3 & $\begin{array}{l}4 \\
5 \\
0\end{array}$ & $\begin{array}{l}15 \\
15 \\
15\end{array}$ & $\begin{array}{l}7 \\
9 \\
0\end{array}$ & $\begin{array}{c}47 \\
60 \\
0\end{array}$ & $\begin{array}{c}1.68 \\
1.99 \\
0\end{array}$ & $\begin{array}{l}6 \\
5\end{array}$ & $\begin{array}{l}1 \\
4\end{array}$ & & $\begin{array}{l}2 \\
2\end{array}$ & 1 & $\begin{array}{l}1 \\
3\end{array}$ & 2 & & 1 & $\begin{array}{l}7 \\
9\end{array}$ & $\begin{array}{l}1 \\
3\end{array}$ \\
\hline LS4 & A. fulvescens & 5 & 9 & 3 & $\begin{array}{l}1 \\
4 \\
0 \\
\end{array}$ & $\begin{array}{l}15 \\
15 \\
15 \\
\end{array}$ & $\begin{array}{c}1 \\
15 \\
0 \\
\end{array}$ & $\begin{array}{c}7 \\
100 \\
0 \\
\end{array}$ & $\begin{array}{c}2.56 \\
1.91 \\
0 \\
\end{array}$ & 8 & 7 & 1 & & & 9 & 2 & & 1 & 13 & 4 \\
\hline
\end{tabular}



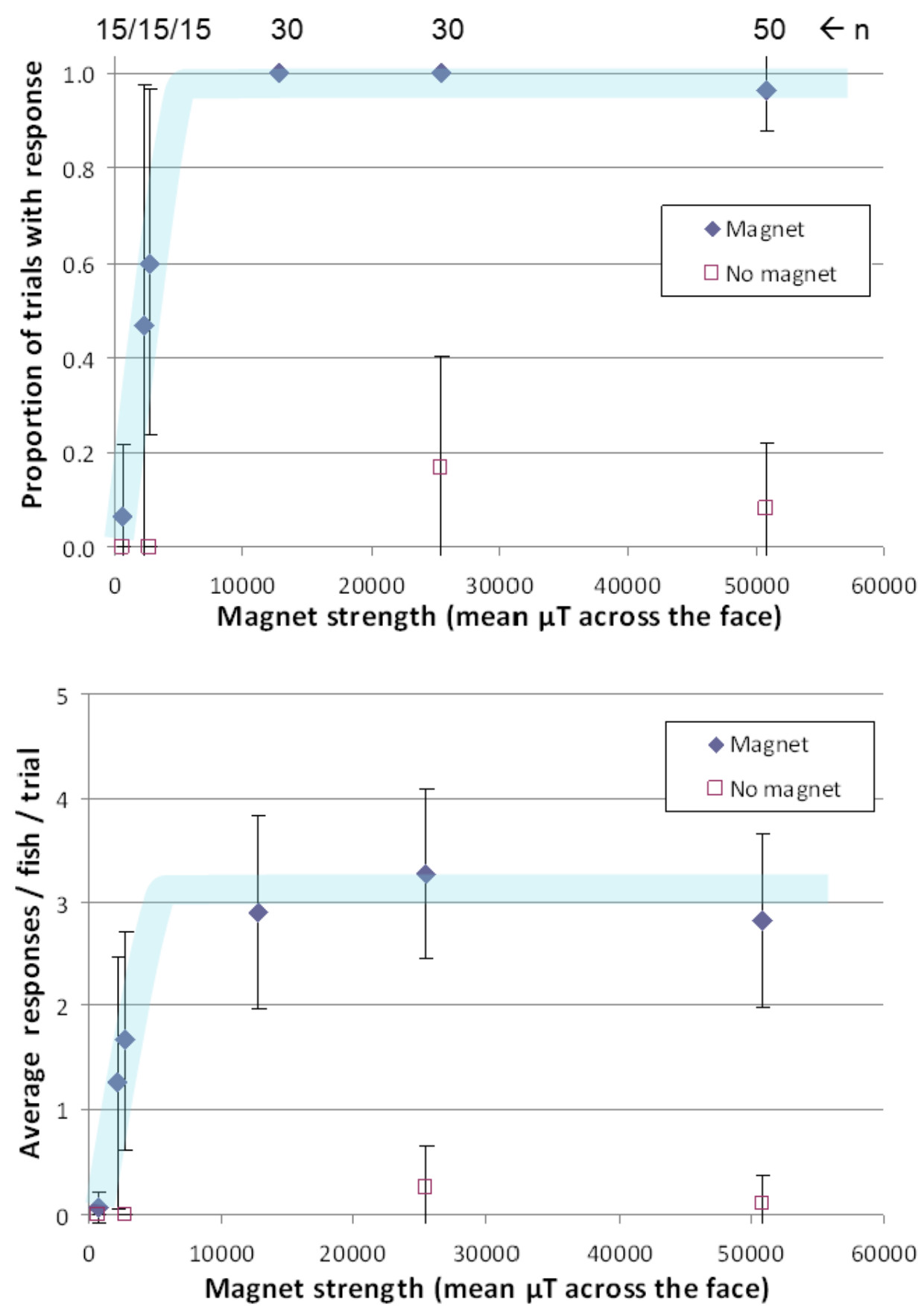

Figure 13. Proportion of trials in which juvenile lake sturgeon responded to sudden exposure to variable EMF, and mean number of responses by fish and trial. 
sturgeon in the same trial (LS4) exhibited some reaction to the field at $4 \%$ of maximum strength. Some control fish exhibited altered behaviors as well; 8 and 17\% of the sturgeon in LS1 and LS2 respectively displayed some response when they swam in the area of the disconnected electromagnet.

When all experimental conditions and replicates are combined, lake sturgeon usually exhibited some type of startle behavior in response to the sudden appearance of the AC-generated magnetic field. Startle reactions, ranging from pectoral fin flare to thrashing (Table 3) were seen in 250 of the 280 lake sturgeon observations (Table 4). Often the startle responses were accompanied by behaviors indicating that the fish were attracted to the EM field (193 of the 280 total observations). Behaviors interpreted as indicative of EMF avoidance were rare among the juvenile lake sturgeon in these tests, occurring in only 35 of the observations.

Overall, juvenile sturgeon behaviors observed most frequently in response to the variable magnetic field (Figure 14 ) included pectoral fin flare (30.5\% of all observations), slowing or gliding (22.6\%), body spasms (20\%), remaining in area of magnet (15.5\%), and sudden stops near the magnet $(14.2 \%)$. Behaviors observed less often included C-start without escaping the stimulus area (7.6\%), "jumping" away from the stimulus area without swimming (7.1\%), thrashing (6.8\%), spasm of the tail only $(2.6 \%)$, C-start reaction followed by escape of the stimulus area (2.1\%), and increase in swimming speed (0.5\%). Some of these behaviors were also seen in the control fish (experimental series LS1 and LS2), albeit at a much lower incidence than observed among EMF-exposed sturgeon.

Comparison of the durations of reaction by means of one-way analysis of variance on ranks revealed statistically significant differences among test and control groups. Juvenile sturgeon exposed to variable magnetic fields at $100 \%, 50 \%, 25 \%, 5 \%, 4 \%$, and $1 \%$ of the maximum value exhibited longer reaction times than control groups $(P=0.002)$.

\section{CONCLUSIONS AND RECOMMENDATIONS}

Laboratory experiments conducted in FY 2010 found no evidence that three common freshwater taxa (the snail Elimia clavaeformis, the clam Corbicula fluminea, and the fathead minnow Pimephales promelas) were either attracted to or repelled by a static (DC) magnetic field (Cada et al. 2011). Similarly, further experiments in FY 2011 with juvenile sunfish, channel catfish, and striped bass did not detect a significant change in position relative to controls (Table 5). Our results suggest that the predicted EMF that may be created by a single submerged DC transmission cable from an HK project would not seriously affect the behavior of common freshwater species.

The variable EMF associated with AC currents caused little of no behavioral effects in paddlefish, a species that is known to be highly sensitive to electrical fields. However, another fish of known EMF sensitivity, the sturgeon, displayed temporarily altered swimming behavior when exposed to variable magnetic fields. Other than the brief reactions by sturgeon to the variable fields reported here, no longer-term changes in behavior or mortalities were observed. 


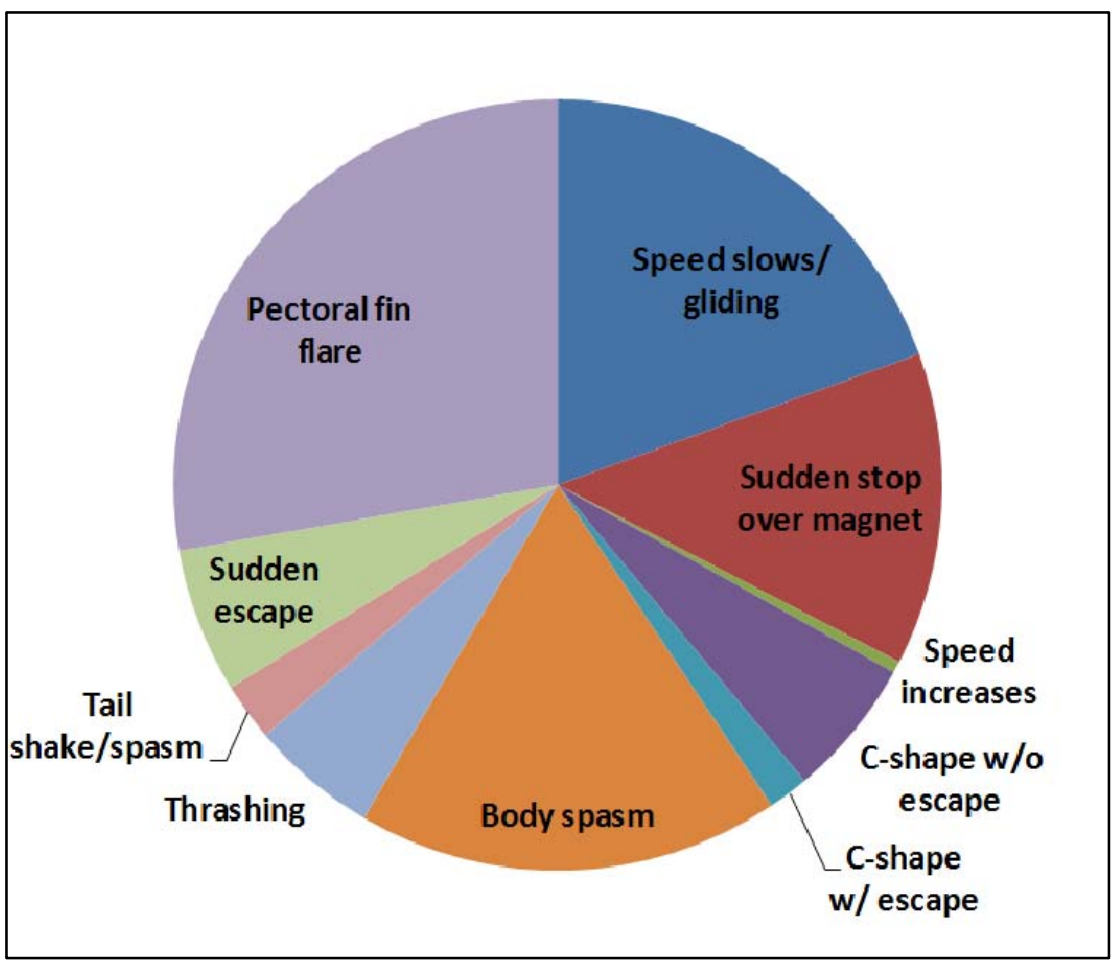

Figure 14. Juvenile sturgeon behavior responses observed most frequently in response to the variable magnetic field.

Table 5. Summary of responses to static magnetic field exposure in examined fish species.

\begin{tabular}{|c|c|c|c|}
\hline Species & $\begin{array}{l}\text { Magnet } \\
\text { Type }\end{array}$ & $\begin{array}{c}\text { Distribution } \\
\text { Effect }\end{array}$ & $\begin{array}{l}\text { Activity } \\
\text { Effect }\end{array}$ \\
\hline & DC & & \\
\hline Fathead minnow & $\begin{array}{c}\max .36,000 \mu \mathrm{T} \\
D C\end{array}$ & NO & YES \\
\hline Redear sunfish & $\begin{array}{c}\max .36,000 \mu T \\
A C\end{array}$ & NO & NO \\
\hline Redear sunfish & $\begin{array}{c}\max .1,500 \mu \mathrm{T} \\
\mathrm{AC}\end{array}$ & NO & NO \\
\hline Lake sturgeon & $\begin{array}{c}\max .1,500 \mu \mathrm{T} \\
\text { DC }\end{array}$ & NO & NO \\
\hline Striped bass & $\begin{array}{c}\max .36,000 \mu \mathrm{T} \\
D C\end{array}$ & NO & NO \\
\hline Channel catfish & $\max .36,000 \mu \mathrm{T}$ & NO & NO \\
\hline
\end{tabular}


Passive electroreception is widespread in fish, occurring in numerous orders of cartilaginous and nonteleost bony fishes (Collin and Whitehead 2004); this capability has not been reported for most teleosts (Wilkens and Hofmann 2005). Of the species we tested, paddlefish and members of the sturgeon and catfish families are known to be electrosensitive. The absence of responses to the magnetic (B) and consequent induced electrical fields (iE) among fathead minnows, sunfish, and striped bass is perhapsnot surprising because there is no indication from the literature that these taxa have specialized magnetosensitive or electrosensitive tissues. However, the lack of response among paddlefish to the strong, variable electromagnetic field was unexpected. This species is extremely sensitive to very small electrical fields produced by the movement of prey items such as Daphnia (Wojtenek et al. 2001; Wilkens and Hofmann 2007), and paddlefish are known to avoid metal rods placed in the water because of their electrical field potential (Gurgens et al. 2000). Because of this sensitivity, we expected the paddlefish to react to the induced electrical field created by their swimming through the strong ACgenerated magnetic fields in the test tank. Wojtenek et al. (2001) noted that the zooplankton prey of paddlefish produce both direct current and oscillating alternating current electric fields containing multiple frequencies and amplitudes. They carried out experiments to test the sensitivity of paddlefish to electrical stimuli at frequencies ranging from 0.1 to $50 \mathrm{~Hz}$. They found that the maximum behavioral responses of paddlefish (i.e., strikes at electrical stimuli) occurred between 5 and $15 \mathrm{~Hz}$, and decreased both above and below this range. Also, the intensities of the electrical stimuli were influential; feeding strikes peaked at a peak-to-peak amplitude of $0.25 \mu \mathrm{A}$ and declined at both lower and higher amplitudes (Wojtenek et al. 2001). It is possible that the frequencies and intensities of the induced electrical signals created by the strong, $60-\mathrm{Hz}$ electromagnet in our experiments were beyond the range that is readily detected by paddlefish.

Similarly, because the brown bullhead (Ameiurus nebulosus) is known to be sensitive to very weak DC fields (Roth 1968; Peters and Bretschneider 1972; Peters and van Wijland 1974; Eeuwes et al. 2001), it might be expected that other members of the Ictaluridae (e.g., channel catfish) would also have this sensory ability. In the cited studies of the brown bullhead, the DC field was generated in experimental arenas using electrodes, whereas in our experiments the channel catfish were exposed to an electrical field created by magnetic induction. An induced electrical field (iE) is the more likely potential stimulus for fish in the vicinity of an HK project with well-shielded electrical components, but an iE may be not be detected in the same way as electrical currents passing directly through the water between electrodes. Nonetheless, Brown et al. (1984) demonstrated stimulation of electroreceptors in Turkistan catfish (Glyptosternum reticulatum) from both DC currents and movement of a permanent bar magnet (creating an iE field) over the fish. The channel catfish in our experiments may have sensed the iE produced by their swimming through the static magnetic field and simply not have reacted to the stimulus by changing their activity level or distribution relative to the magnet.

The reactions of lake sturgeons that we observed are consistent with studies of Asian sturgeon species. Basov (1999) exposed sterlet and Russian sturgeon to weak electrical fields with frequencies ranging from 0.1 to $50 \mathrm{~Hz}$. An alternating current field of up to $7 \mathrm{mV} / \mathrm{cm}$ was created between two buried electrodes in an experimental tank, and the swimming behavior of the sturgeon passing through the electrode zone was quantified. At low field electrical field intensities (roughly, less than $3.0 \mathrm{mV} / \mathrm{cm}$ ), the 
sturgeon exhibited orientation and search responses, i.e., they were attracted to the field. At higher field intensities the fish attempted to escape from the area of the electrodes; behaviors reported by Basov (1999) included quivering of the pectoral fins, strong excitation, and sudden escape from the electrode zone. At higher AC frequencies $(50 \mathrm{~Hz})$, the field intensity that elicited an escape response in these two sturgeon species was lower than at lower $A C$ frequencies $(0.1$ to $18 \mathrm{~Hz}$ ). In a subsequent field study below a hydroelectric dam, Basov (2007) observed the movements of sturgeon in an area of the river in which an AC field had been induced by overhead $50 \mathrm{~Hz}$ power lines. Induced electrical fields directly under the power lines were as high as $0.4 \mathrm{mV} / \mathrm{cm}$, and decreased with increasing depth and horizontal distance. Few sturgeon (or other fish) were found in the area with the highest induced current, and various sturgeon species were found to congregate in an area of the river where the electrical field intensity was estimated to be $0.03-0.04 \mathrm{mV} / \mathrm{cm}$. Although other environmental factors may have accounted for the distribution of the sturgeon below the dam (e.g., hydraulic and bottom substrate features, food availability), the low-intensity induced electric field did not appear to elicit an avoidance response.

Laboratory studies have shown that the electrosensitivities of fish are related to both field intensity and the frequency of alternating currents. Depending on the species, the maximum reactions to an electromagnetic field may occur at intermediate values of frequency and intensity, and drop off at both higher and lower values. The static and variable magnetic fields that we tested in these experiments were potentially much stronger than those that would be experienced by fish near an HK project, although there is uncertainty about this owing to a lack of actual published measurements of HK technologies and their associated transmission cables. Further studies of the responses of freshwater fish to EMF produced by HK technologies await a better definition of the nature and strength of the emitted fields. If these parameters are found to be outside of the range of values detectable by fish, concerns about the constraints to development of HK projects posed by EMF emissions may be resolved.

The biological response experiments to date have used simple fields issuing from a single source, as might be created from an underwater cable, for example. Different configurations of cables and other electricity generating and transmitting components could create very different fields in terms of field strength and shape (Kadomskaya et al. 2005). More complex and potentially stronger EMF will be emitted from multiple parallel or overlapping cables or other components of the HK device; these types of fields have not been tested. Additional studies of HK generators and multiple cables are needed, beginning with model predictions of various conformations of electromagnetic fields, and continuing through field-site measurements of EMF at an operating HK prototype. Whereas it will be difficult to reduce the EMF from $\mathrm{HK}$ generators, mitigation of EMF effects on aquatic organisms from cable might be accomplished by different configurations and/or burying the cables in sediments (as suggested by the predictive models of Kadomskaya et al. 2005). 


\section{REFERENCES}

Asano, M. and I. Hanyu. 1986. Biological significance of electroreception in Japanese catfish. Bulletin of the Japanese Society of Scientific Fisheries. 52(5):795-800.

Baranyuk, G. V. 1981. Orientation of the catfish in uniform and nonuniform electric fields. Neuroscience and Behavioral Physiology 11(5):459-463.

Basov, B. M. 1999. Behavior of starlet Acipenser ruthenus and Russian sturgeon A. gueldenstaedtii in low-frequency electric fields. Journal of Ichthyology 39(9):782-787.

Basov, B. M. 2007. On electric fields of power lines and on their perception by freshwater fish. Journal of Ichthyology 47(8):656-661.

Brown, H. R., G. N. Andrianov, and A. Mamadaliev. 1984.Electroreception in the Turkistan catfish. Experentia 40:1366-1367.

Cada, G., M. Bevelhimer, K. Riemer, and J. Turner. 2011. Effects on Freshwater Organisms of Magnetic Fields Associated with Hydrokinetic Turbines. ORNL/TM-2011/244. Oak Ridge National Laboratory, Oak Ridge, Tennessee. 38 p. + Appendix.

CMACS (Centre for Marine and Coastal Studies). 2003. A baseline assessment of electromagnetic fields generated by offshore windfarm cables. COWRIE Report EMF-01-2002 66. Liverpool, UK. http://www.offshorewind.co.uk

Collin, S. P. and D. Whitehead. 2004. The functional roles of passive electroreception in non-electric fishes. Animal Biology 54(1):1-25.

DOE (U.S. Department of Energy). 2009. Report to Congress on the Potential Environmental Effects of Marine and Hydrokinetic Energy Technologies. December 2009. 89 p. + appendices. http://www1.eere.energy.gov/windandhydro/marine hydro market acceleration.html

Eeuwes, L. B. M., R. C. Peters, F. Bretschneider, and W. J. G. Loos. 2001. Electroreception in catfish Ictalurus nebulosus in uniform and non-uniform DC fields: detection threshold and body length. Belgian Journal of Zoology 131 (Supplement 2):73-78.

FERC (Federal Energy Regulatory Commission). 2012. Federal Energy Regulatory Commission, Hydrokinetic Projects. Available online: http://www.ferc.gov/industries/hydropower/indusact/hydrokinetics.asp. (Accessed March 2012).

Gill, A. B., I. Gloyne-Phillips, K. J. Neal, and J. A. Kimber. 2005. The Potential Effects of Electromagnetic Fields Generated by Sub-Sea Power Cables Associated with Offshore Wind Farm Developments on Electrically and Magnetically Sensitive Marine Organisms - A Review. COWRIE Report EM Field 2-062004. http://www.offshorewind.co.uk 
Gill, A. B., Y. Huang, I. Gloyne-Philips, J. Metcalfe, V. Quayle, J. Spencer, and V. Wearmouth. 2009. COWRIE 2.0 Electromagnetic Fields (EMF) Phase 2: EMF-sensitive fish response to EM emissions from sub-sea electricity cables of the type used by the offshore renewable energy industry. Commissioned by COWRIE Ltd (project reference COWRIE-EMF-1-06). http://www.offshorewind.co.uk

Gurgens, C., D. F. Russell, and L. A. Wilkens. 2000. Electrosensory avoidance of metal obstacles by the paddlefish. Journal of Fish Biology 57:277-290.

Kadomskaya, K. P., S. A. Kandakov, and Y. A. Lavrov. 2005. Electromagnetic compatibility of underwater cable lines of various designs with ichtyofauna. Power Tech, 2005 IEEE Russia. 4 p.

Likens, L. A. and M. H. Hofmann. 2007. The paddlefish rostrum as an electrosensory organ: A novel adaptation for plankton feeding. Bioscience 57(5):399-407.

Normandeau, E., T. Tricas, and A. Gill. 2011. Effects of EMFs from Undersea Power Cables on Elasmobranchs and Other Marine Species. U.S. Department of the Interior, Bureau of Ocean Energy Management, Regulation, and Enforcement, Pacific OCS Region, Camarillo, CA. OCS Study BOEMRE 2011-09.

Peters, R. C. and F. Bretschneider. 1972. Electric phenomena in the habitats of the catfish Ictalurus nebulosus LeS. Journal of Comparative Physiology 81:345-362.

Peters, R. C. and F. van Wijland. 1974. Electro-orientation in the passive electric catfish, Ictalurus nebulosus LeS. Journal of Comparative Physiology 92:273-280.

Roth, A. 1968. Electroreception in the catfish, Amiurus nebulosus. Zeitschriftfürvergleichende Physiologie 61:196-202.

Wilkens, L. A. and M. H. Hofmann. 2005. Behavior of animals with passive, low-frequency electrosensory systems. Chapter 9, In: Electroreception. T. H. Bullock, C. D. Hopkins, A. N. Popper, and R. R. Fay (eds). Springer Handbook of Auditory Research, Vol. 21. Springer. 472 p.

Wilkens, L. A. and M. H. Hofmann. 2007. The paddlefish rostrum as an electrosensory organ: a novel adaptation for plankton feeding. Bioscience 57(5):399-407.

Wojtenek, W., X. Pei, and L. A. Wilkens. 2001. Paddlefish strike at artificial dipoles simulating the weak electric fields of planktonic prey. Journal of Experimental Biology 204:1391-139. 